\title{
Preexisting memory CD4 T cells in naïve individuals confer robust immunity upon hepatitis B vaccination
}

\author{
George Elias ${ }^{1,2 * \dagger}$, Pieter Meysman 2,3,4†, Esther Bartholomeus ${ }^{2,5 \dagger}$, \\ Nicolas De Neuter ${ }^{2,3,4}$, Nina Keersmaekers ${ }^{2,6}$, Arvid Suls ${ }^{2,5}$, Hilde Jansens, \\ Aisha Souquette $^{8}$, Hans De Reu ${ }^{1,9}$, Marie-Paule Emonds ${ }^{10}$, Evelien Smits ${ }^{1,9}$, \\ Eva Lion ${ }^{1,9}$, Paul G Thomas ${ }^{8}$, Geert Mortier ${ }^{2,5}$, Pierre Van Damme ${ }^{2,11}$, \\ Philippe Beutels ${ }^{2,6}$, Kris Laukens ${ }^{2,3,4 \dagger}$, Viggo Van Tendeloo ${ }^{1+\ddagger}$, \\ Benson Ogunjimi ${ }^{2,6,12,13 * \dagger}$
}

${ }^{1}$ Laboratory of Experimental Hematology (LEH), Vaccine and Infectious Disease Institute, University of Antwerp, Antwerp, Belgium; ${ }^{2}$ Antwerp Unit for Data Analysis and Computation in Immunology and Sequencing, University of Antwerp, Antwerp, Belgium; ${ }^{3}$ Adrem Data Lab, Department of Mathematics and Computer Science, University of Antwerp, Antwerp, Belgium; ${ }^{4}$ Biomedical Informatics Research Network Antwerp, University of Antwerp, Antwerp, Belgium; ${ }^{5}$ Department of Medical Genetics, University of Antwerp, Antwerp, Belgium; ${ }^{6}$ Centre for Health Economics Research \& Modeling Infectious Diseases, Vaccine \& Infectious Disease Institute (VAXINFECTIO), University of Antwerp, Antwerp, Belgium; ${ }^{7}$ Department of Clinical Microbiology, Antwerp University Hospital, Antwerp, Belgium; ${ }^{8}$ Department of Immunology, St. Jude Children's Research Hospital, Memphis, United States; ${ }^{9}$ Center for Cell Therapy and Regenerative Medicine, Antwerp University Hospital, Antwerp, Belgium; ${ }^{10}$ Histocompatibility and Immunogenetic Laboratory, Rode KruisVlaanderen, Mechelen, Belgium; ${ }^{11}$ Centre for the Evaluation of Vaccination (CEV), Vaccine and Infectious Disease Institute, University of Antwerp, Antwerp, Belgium; ${ }^{12}$ Antwerp Center for Translational Immunology and Virology (ACTIV), Vaccine and Infectious Disease Institute, University of Antwerp, Antwerp, Belgium; ${ }^{13}$ Department of Paediatrics, Antwerp University Hospital, Antwerp, Belgium
*For correspondence: igeorgeelias@gmail.com (GE); benson.ogunjimi@uantwerpen. be (BO)

${ }^{\dagger}$ These authors contributed equally to this work

Present address: ${ }^{\ddagger}$ Janssen Research and Development, Immunosciences WWDA Johnson and Johnson, Beerse, Belgium

Funding: See page 19

Preprinted: 25 August 2020 Received: 14 March 2021

Accepted: 07 January 2022

Published: 25 January 2022

Reviewing Editor: Armita Nourmohammad, University of Washington, United States

(c) Copyright Elias et al. This article is distributed under the terms of the Creative Commons Attribution License, which permits unrestricted use and redistribution provided that the original author and source are credited.

\begin{abstract}
Antigen recognition through the T cell receptor (TCR) $\alpha \beta$ heterodimer is one of the primary determinants of the adaptive immune response. Vaccines activate naïve $T$ cells with high specificity to expand and differentiate into memory $T$ cells. However, antigen-specific memory CD4 T cells exist in unexposed antigen-naïve hosts. In this study, we use high-throughput sequencing of memory CD4 TCR $\beta$ repertoire and machine learning to show that individuals with preexisting vaccine-reactive memory CD4 T cell clonotypes elicited earlier and higher antibody titers and mounted a more robust CD4 T cell response to hepatitis $B$ vaccine. In addition, integration of TCR $\beta$ sequence patterns into a hepatitis B epitope-specific annotation model can predict which individuals will have an early and more vigorous vaccine-elicited immunity. Thus, the presence of preexisting memory $T$ cell clonotypes has a significant impact on immunity and can be used to predict immune responses to vaccination.
\end{abstract}

Editor's evaluation 
By using modern high-throughput sequencing this paper demonstrates that the antibody mediated immune responses that are elicited by vaccination are improved by pre-existing memory CD4 $\mathrm{T}$ cell responses. The experimental data are an important contribution and would be useful as a data resource for future research. All reviewers agree that the findings are of great interest to the community.

\section{Introduction}

Antigen recognition through the T cell receptor (TCR) is one of the key determinants of the adaptive immune response (Rudolph et al., 2006). Antigen presentation via major histocompatibility complex $(\mathrm{MHC})$ proteins, together with the right costimulatory and cytokine signals, are responsible for $\mathrm{T}$ cell activation (Curtsinger and Mescher, 2010; Esensten et al., 2016). The TCR $\alpha \beta$ heterodimer binds the peptide-MHC ( $\mathrm{pMHC}$ ) complex and confers the specificity of a $\mathrm{T}$ cell to an epitope. A highly diverse TCR repertoire ensures that an effective $T$ cell response can be mounted against pathogen-derived peptides (Turner et al., 2009). High TCR $\beta$ diversity is generated through V(D)J recombination at the complementary-determining region 3 (CDR3) of TCR $\alpha$ and TCR $\beta$ chains, accompanied with junctional deletions and insertions of nucleotides, further adding to the diversity (Krangel, 2009).

Vaccines activate naïve $T$ cells with high specificity to vaccine-derived peptides and induce $T$ cell expansion and differentiation into effective and multifunctional T cells. This is followed by a contraction phase from which surviving cells constitute a long-lived memory $T$ cell pool that allows for a quick and robust $T$ cell response upon a second exposure to the pathogen (Farber et al., 2014). However, previous studies have shown that a prior pathogen encounter is not a prerequisite for the formation of memory T cells and that CD4 T cells with a memory phenotype can be found in antigen-naive individuals (Su et al., 2013). The existence of memory-like CD4 T cells in naïve individuals (Sewell, 2012) can be explained by molecular mimicry, as the encounter with environmentally derived peptides activates cross-reactive T cells due to the flexible nature of CD4 T cell recognition of the pMHC complex (Wilson et al., 2004). Indeed, work that attempted to replicate the history of human pathogen exposure in mice has shown that sequential infections altered the immunological profile and remodeled the immune response to vaccination (Reese et al., 2016). The existence of memory CD4 T cells specific to vaccine-derived peptides in unexposed individuals might confer an advantage in vaccineinduced immunity. In the present study, we used high-throughput sequencing to profile the memory CD4 TCR $\beta$ repertoire of healthy hepatitis $B(\mathrm{HB})$-naïve adults before and after administration of an $\mathrm{HB}$ vaccine to investigate the impact of preexisting memory CD4 $\mathrm{T}$ cells on the immune response to the vaccine. Based on anti-hepatitis B surface (anti-HBs) antibody titers over 365 days, vaccinees were grouped into early-, late-, and non-converters. Our data reveals that individuals with preexisting vaccine-specific CD4 T cell clonotypes in the memory CD4 compartment had earlier emergence of antibodies and mounted a more vigorous CD4 T cell response to the vaccine. Moreover, we identify a set of vaccine-specific TCR $\beta$ sequence patterns which can be used to predict TCR specificity and in turn, which individuals will have an early and more vigorous response to HB vaccine.

\section{Results}

\section{Vaccinee cohort can be classified into three groups}

Out of 34 vaccinees, 21 vaccinees seroconverted (an anti-HBs titer above $10 \mathrm{IU} / \mathrm{ml}$ was considered protective; Keating and Noble, 2003) at day 60 and were classified as early-converters; nine vaccinees seroconverted at day 180 or day 365 and were classified as late-converters; remaining four vaccinees had an anti-HBs antibody titer lower than $10 \mathrm{lU} / \mathrm{ml}$ at all time points following vaccination and were classified as non-converters (Figure 1 and Figure 1-figure supplement 1A).

Members of Herpesviridae family might alter immune responses to vaccines (Furman et al., 2015). We found no significant differences in cytomegalovirus (CMV), Epstein-Barr virus (EBV), or herpes simplex virus (HSV) seropositivity between the three groups in our cohort (Figure 1-figure supplement 1B). Early-converters were slightly younger than late-converters, and non-converters were notably younger than both early- and late-converters (Figure 1-figure supplement 1C). 
eLife digest Immune cells called CD4 T cells help the body build immunity to infections caused by bacteria and viruses, or after vaccination. Receptor proteins on the outside of the cells recognize pathogens, foreign molecules called antigens, or vaccine antigens. Vaccine antigens are usually inactivated bacteria or viruses, or fragments of these pathogens. After recognizing an antigen, CD4 T cells develop into memory CD4 T cells ready to defend against future infections with the pathogen.

People who have never been exposed to a pathogen, or have never been vaccinated against it, may nevertheless have preexisting memory cells ready to defend against it. This happens because CD4 T cells can recognize multiple targets, which enables the immune system to be ready to defend against both new and familiar pathogens.

Elias, Meysman, Bartholomeus et al. wanted to find out whether having preexisting memory CD4 T cells confers an advantage for vaccine-induced immunity. Thirty-four people who were never exposed to hepatitis B or vaccinated against it participated in the study. These individuals provided blood samples before vaccination, with 2 doses of the hepatitis B vaccine, and at 3 time points afterward. Using next generation immune sequencing and machine learning techniques, Elias et al. analyzed the individuals' memory CD4 T cells before and after vaccination.

The experiments showed that preexisting memory CD4 T cells may determine vaccination outcomes, and people with more preexisting memory cells develop quicker and stronger immunity after vaccination against hepatitis B. This information may help scientists to better understand how people develop immunity to pathogens. It may guide them develop better vaccines or predict who will develop immunity after vaccination.

\section{Unperturbed diversity in memory CD4 T cell repertoire following vaccination}

A genomic DNA-based TCR $\beta$ sequence dataset of memory CD4 T cells isolated from peripheral blood was generated from a cohort of 33 healthy vaccinees (see Materials and methods for details) right before vaccination (day 0 ) and 60 days after administration of the first dose of HB vaccine (30 days after administration of the second vaccine dose).

Between $4.54 \times 10^{4}$ and $3.92 \times 10^{5}$ productive TCR $\beta$ sequence reads were obtained for each vaccinee at each time point (Figure 2-figure supplement 1A). Between 30,000 and 90,000 unique TCR $\beta$ sequences were sequenced for each vaccinee at each time point (Figure 2-figure supplement 1B). As expected, considering the extremely diverse memory CD4 T cell repertoire (Klarenbeek et al., 2010), less than $20 \%$ of the TCR $\beta$ sequences is shared between the time points for each vaccinee (Figure 2-figure supplement 1C).

The diversity of the memory CD4 T cell repertoire of each vaccinee at the two time points was explored, but neither the breadth of the memory CD4 TCR $\beta$ repertoire nor the Shannon equitability index was found to have been impacted by the vaccine at day 60 (Figure 2A).

\section{Unique vaccine-specific TCR $\beta$ sequences are trackable within memory CD4 $T$ cell repertoire and increase following vaccination}

Peripheral blood mononuclear cells from day 60 were labeled with carboxyfluorescein succinimidyl ester (CFSE), a dye that enables tracking of cell proliferation, and stimulated with a pool of peptides spanning HB surface antigen (HBsAg). After day 7 of in vitro expansion, we sorted CFSE ${ }^{\text {low }}$ CD4 T cells (Becattini et alo, 2015) and extracted mRNA for quantitative assessment of HBsAg-specific TCR $\beta$ clonotypes by sequencing (see Materials and methods for details). The establishment of a set of vaccine-specific TCRs enables their tracking within memory CD4 T cell repertoires from day 0 to day 60 , based on their CDR3 $\beta$ amino acid sequences.

We detected a significant increase in the breadth of $\mathrm{HBsAg}$-specific TCR $\beta$ sequences at day 60 postvaccination compared to pre-vaccination (mean increase $=107.9 \%, 95 \% \mathrm{Cl}=62.2-358.5 \%$ ) (Figure 2B and Figure 2-figure supplement 1D). This increase far exceeded a baseline control of varicellazoster virus (VZV)-specific TCR $\beta$ sequences established in an identical manner (mean difference $=2.1 \%$, $95 \% \mathrm{Cl}=-6.6 \%$ to $12.4 \%$ ). The HBsAg-specific increase was found to be significant when compared 
A

$1^{\text {st }}$ and $2^{\text {nd }}$ doses of hepatitis vaccine

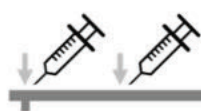

03060

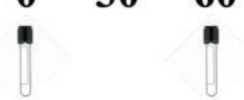

Blood collection

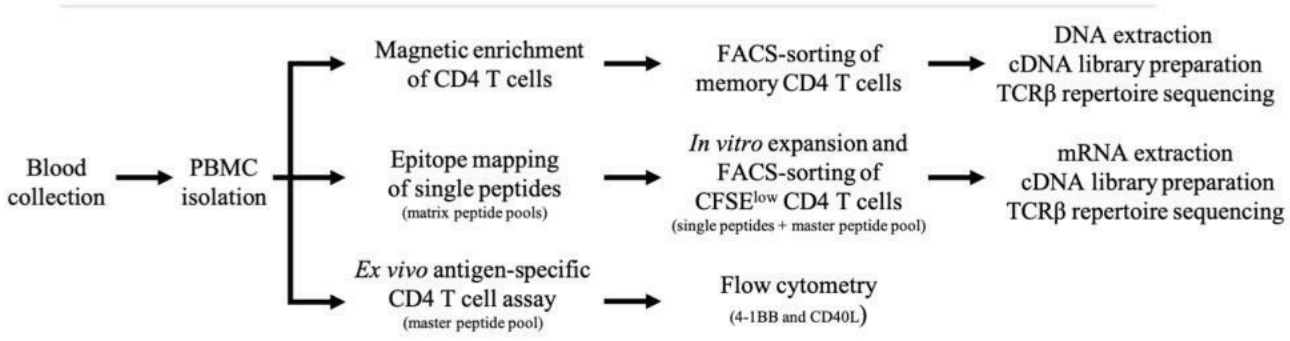

Groups in the cohort determined by anti-HBs antibody titer serocoversion

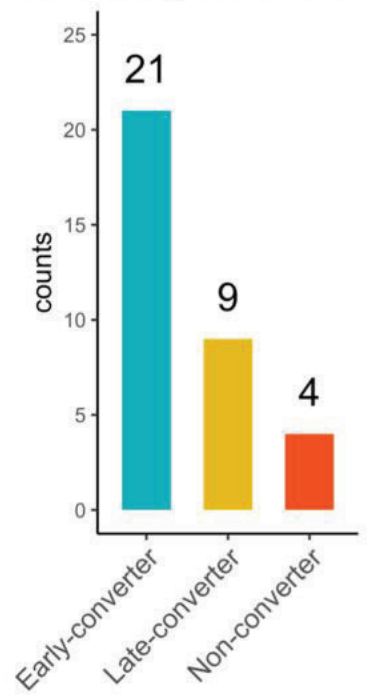

Figure 1. Hepatitis B vaccination (Engerix-B) study design. (A) Hepatitis B (Engerix-B) vaccination and experimental design. (Top) Timeline of vaccination and blood collection. (Bottom) Memory CD4 T cells were magnetically enriched and FACS-sorted from two time points (day 0 and day 60) for TCR $\beta$ repertoire sequencing. Peptide matrix pools were used to map CD4 T cell epitopes of the vaccine from peripheral blood mononuclear cells (PBMCs) collected at day 60 and to select single peptides. After 7 days of in vitro expansion, single peptide-specific and master peptide pool-specific CFSE ${ }^{\text {low }}$ CD4 T cells from PBMCs collected at day 60 were FACS-sorted in two technical replicates for TCR 3 repertoire sequencing. PBMCs collected at days $0,60,180$, and 365 were stimulated with the master peptide pool (HBsAg) and assessed for converse expression of 4-1BB and CD40L by flow cytometry. (B) Vaccinee cohort can be classified into three groups as determined by anti-hepatitis B surface (anti-HBs) titer over four times points. Earlyconverters seroconverted at day 60, late-converters seroconverted at day 180 or day 365 , and non-converters did not have an anti-HBs titer higher than $10 \mathrm{IU} / \mathrm{ml}$ at any of the time points.

The online version of this article includes the following figure supplement(s) for figure 1:

Figure supplement 1. Serological memory to hepatitis B vaccine and vaccinee groups within the cohort.

to this VZV baseline (Wilcoxon p-value 6.3e-05). When considered across the different groups, the increase was found to be significantly different from the VZV baseline for the early-converters (mean $=$ $151.9 \%, 95 \% \mathrm{Cl}=78.9-342.0 \%$, Wilcoxon Bonferroni-corrected p-value 8.64e-5) and non-converters (mean $=67.6 \%, 95 \% \mathrm{Cl}: 37.6-89.7 \%$, Wilcoxon Bonferroni-corrected $\mathrm{p}$-value 0.03), but not for the late-converters $($ mean $=18.8 \%, 95 \% \mathrm{Cl}=3.6-41.8 \%$, Wilcoxon Bonferroni-corrected $p$-value 0.257 ).

As HBsAg-specific TCR $\beta$ sequences were already detected in the memory CD4 T cell repertoire prior to vaccination, we sought to determine whether the vaccination induced an expansion of those sequences. Based on the frequency of vaccine-specific TCR $\beta$ sequences within the memory CD4 T cell repertoire, the data does not support a vaccine-induced expansion of preexisting vaccine-specific TCR $\beta$ sequences (Figure 2-figure supplement 1E). Thus, although we see a rise in vaccine-specific TCR $\beta$ T cells from day 0 to day 60 , this cannot be attributed to an expansion of the vaccine-specific TCR $\beta$ clonotypes found at day 0 but rather the recruitment of new TCR $\beta$ clonotypes, as visualized for one vaccinee in Figure $2 \mathrm{C}$.

It makes sense to not only look at the difference in vaccine-specific TCR $\beta$ sequences between time points, but also explore whether there are differences in the proportion of HBsAg-specific clones in the memory repertoire between early-converters, late-converters, and non-converters after vaccination. In this case, to allow for a between-vaccinees comparison (in contrast to the within-vaccinees time point comparison), we calculate the overlap coefficient, where $\mathrm{HBsAg}$-specific sequences in 
A
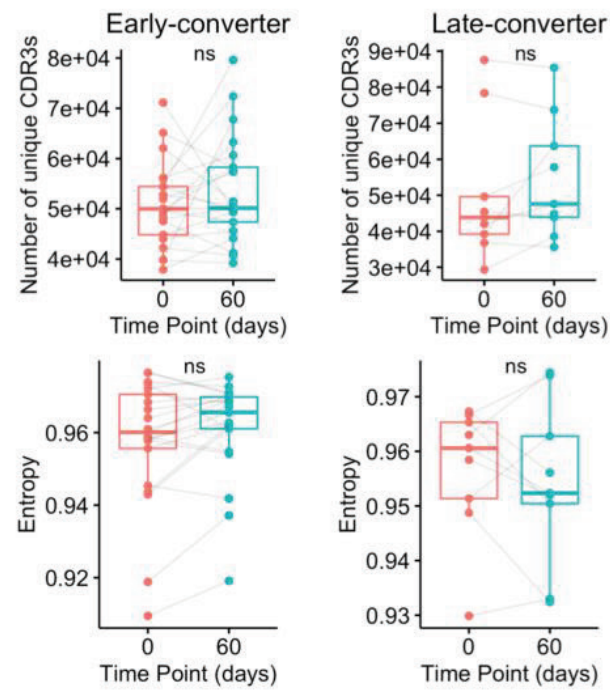

C

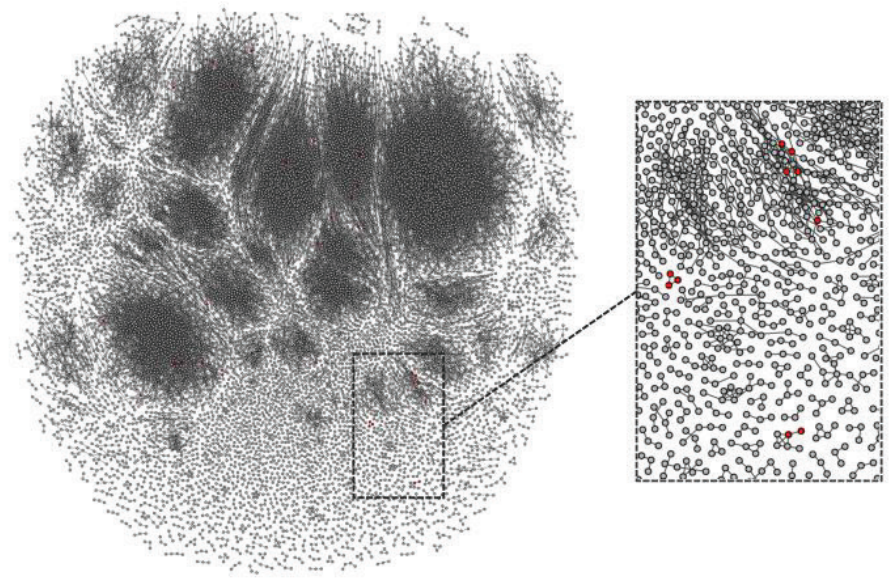

B

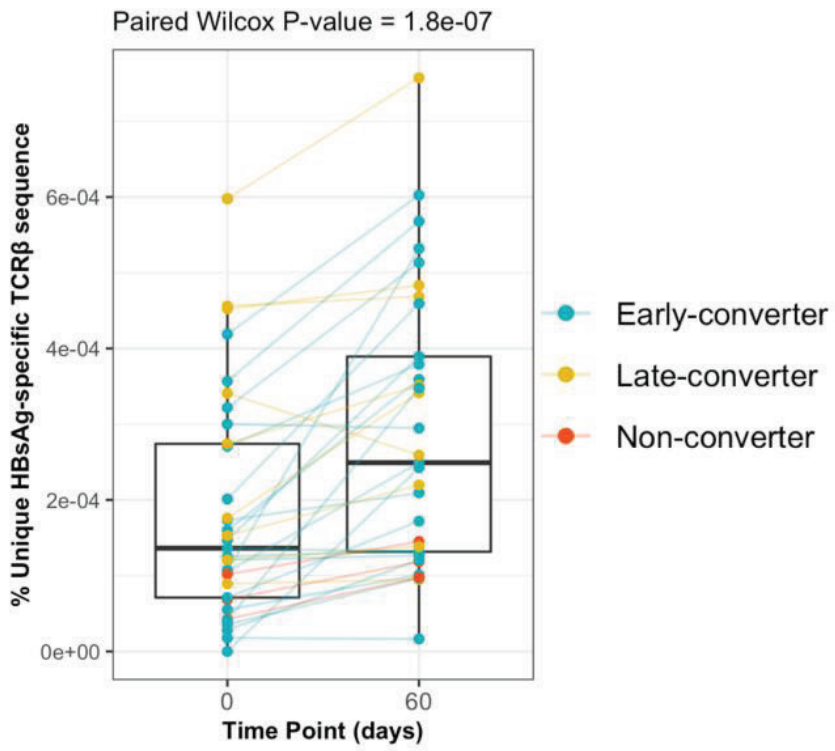

D Day 60

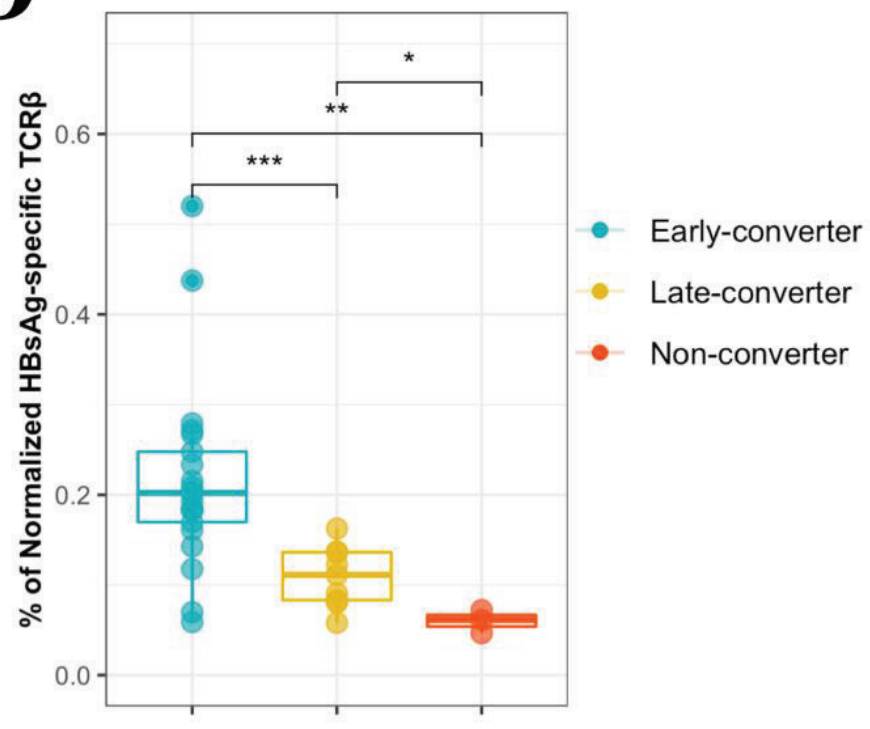

Figure 2. CD4 T cell memory T cell receptor $\beta$ (TCR $\beta$ ) repertoire and vaccine-specific TCR $\beta$ clonotypes. (A) Comparison of the memory CD4 TCR $\beta$ repertoire diversity, as shown by breadth (number of unique TCRs) and entropy (Shannon equitability index) between day 0 and day 60 . Indices are available in Figure 2-source data 1. (B) Frequency of unique vaccine-specific TCR $\beta$ sequences out of total sequenced TCR $\beta$ sequences between two time points for all vaccinees colored by group. Frequencies are available in Figure 2-source data 2. (C) Sequenced CD4+ TCR memory repertoire of vaccinee H35 at day 60. Each TCR clonotype is represented by a node. TCRs are connected by an edge if their Hamming distance is one. Only clusters with at least three TCRs are shown. TCR clonotypes in red are the vaccine-specific TCR $\beta$ sequences that were not present prior to vaccination. (D) Frequency of vaccine-specific TCR $\beta$ sequences within memory CD4 T cell repertoire normalized by number of HBsAg-specific TCR $\beta$ sequences found for each vaccinee at time point 60. Frequencies are available in Figure 2-source data 3.

Figure 2 continued on next page 
Figure 2 continued

The online version of this article includes the following source data and figure supplement(s) for figure 2:

Source data 1. Breadth and entropy of T cell receptor $\beta$ (TCR $\beta)$ repertoire.

Source data 2. Frequency of unique hepatitis B surface antigen (HBsAg)-specific T cell receptor $\beta$ (TCR $\beta$ ) sequences.

Source data 3. Frequency of normalized hepatitis B surface antigen (HBsAg)-specific T cell receptor $\beta$ (TCR $\beta$ ) sequences.

Figure supplement 1. CD4 T cell memory T cell receptor $\beta$ (TCRß) repertoire and vaccine-specific TCR $\beta$ clonotypes.

the CD4 T cell memory repertoire are normalized by the number of HBsAg-specific TCR $\beta$ found for each vaccinee. From this analysis, it can be concluded that there is a difference in HBsAg-specific TCR $\beta$ at day 60 between the three groups (Figure 2D) (ANOVA p-value $=0.00238$ ). A Wilcoxon test between early-converters and other vaccinees shows a significant $p$-value of 0.000473 , indicating that early-converters have a higher relative frequency of vaccine-specific TCR $\beta$ sequences present in their memory CD4 T cell repertoire at day 60 compared to vaccinees from the two other groups in the cohort.

In summary, vaccine-specific TCR $\beta$ sequences increased in breadth following vaccination in earlyconverters and constituted a significantly higher proportion of the memory CD4 T cell compartment post-vaccination.

\section{HBsAg single peptide-specific TCR $\beta$ identification allows predictive modelling of early-converters prior to vaccination}

To quantify the $\mathrm{T}$ cell response at the level of individual peptides that make up the HBsAg, a peptide matrix designed to cover 54 overlapping peptides of the HBsAg was used to extract peptide-specific T cells using a CD40L/CD154 activation-induced marker (AIM) assay (see Materials and methods for details). The top six peptides for each individual were selected for an in vitro peptide-specific CD4 T cell expansion and sorting for TCR sequencing (Supplementary file 2 and Figure 3-figure supplement 1). In this manner, TCR $\beta$ sequences were identified for T cells reactive against 44 single $\mathrm{HBsAg}$ peptides. These were not uniformly distributed across the HBsAg amino acid sequence, with the most prominent epitopes covering the regions 1-15, 129-144, 149-164, 161-176, 181-200, $213-228$. For each of those regions, more than 10 individuals had a strong $T$ cell response and more than 150 unique TCR $\beta$ sequences could be identified (Figure $3 A$ ).

These peptide-specific TCR $\beta$ sequences can be utilized in a peptide-TCR interaction classifier to identify other TCR $\beta$ that are likely to react against same HBsAg epitopes, as it has been shown that similar TCR $\beta$ sequences tend to target the same epitopes (De Neuter et al., 2018; Meysman et al., 2019). These classifications were integrated into a model which outputs a ratio $R_{\text {hbs, }}$ which represents the amount of HBsAg epitope-specific TCR sequences in an individual repertoire. The ratio is equal to the breadth of unique predicted HBsAg peptide-specific TCR $\beta$ divided by a normalization term for putative false positive predictions due to bystander activations in the training data set. The memory repertoire at day 60 shows that early-converters tend to have a higher breadth of putative $\mathrm{HBsAg}$ peptide-specific TCR $\beta$, while late-converters tend to have relatively more putative false positives as per the normalization term (Figure $3 \mathrm{~B}$ ). The ratio of these two terms $R_{\text {hbs }}$ therefore shows a significant difference between early- and the late-converters at day 60 (one-sided Wilcoxon-test $p$-value = 0.0313, Figure 3C). Furthermore, searching for HBsAg peptide-specific clonotypes in the memory repertoires prior to vaccination (day 0 ) results in a $R_{\text {hbs }}$ with a similar difference (one-sided Wilcoxontest $p$-value $=0.0010$, Figure $3 D$ ). In this manner, the presence of HBsAg peptide-specific clonotypes as defined by the ratio $R_{\text {hbs }}$ can be used as a classifier to distinguish early- from late-converters prior to vaccination (Figure 3E), with an area under the curve (AUC) of 0.825 (95\% Cl: $0.657-0.994$ ) in a leave-one-out cross-validation setting. A model in which age-matched vaccinees were included from early- and late-converters returned a similar receiver operating characteristic (ROC) curve, suggesting that this signal is not age-dependent (Figure 3F).

While $R_{\text {hbs }}$ is able to differentiate between early- and late-converters, it seems to be worse at distinguishing non-converters. This is mainly due to a single non-converter vaccinee $(\mathrm{H} 21)$ with a high $R_{\text {hbs, }}$ signifying a high number of putative HBsAg peptide-specific TCR $\beta$ in their memory repertoire. 


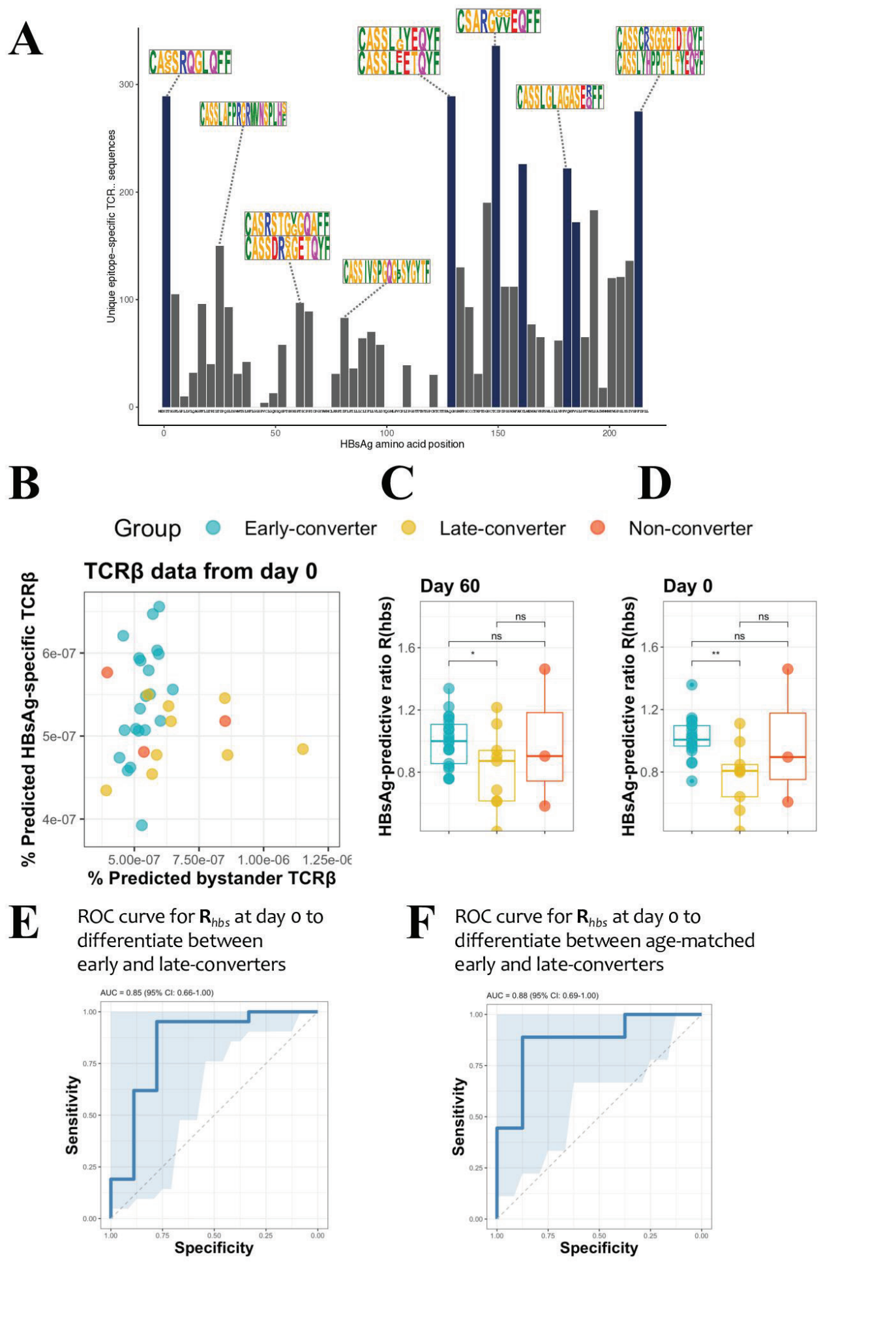

Figure 3. Hepatitis B surface antigen (HBsAg) peptide-specific T cell receptor $\beta$ (TCRß) identification and predictive potential of $R_{h b s .}$ (A) Overview of the detected HBsAg epitope-specific TCR 3 sequences. Each bar corresponds to unique TCR 3 sequences found against a single $15 \mathrm{mer} H \mathrm{Hs} \mathrm{Ag}$ peptide, with 11 amino acid overlap to each subsequent peptide. Bars in blue denote those epitopes for which 10 or more volunteers had a strong T cell reaction. Motif logos on top of bars denote a sampling of the most common TCR $\beta$ amino acid sequence motifs for those epitopes. (B) Scatter Figure 3 continued on next page 
Figure 3 continued

plot with the frequency of predicted HBsAg epitope-specific and bystander TCR $\beta$ sequences at day 60 . These make up respectively the numerator and denominator of the HBsAg-predictive ratio, $R_{h b s}$. Predictions done as a leave-one-out cross-validation. Each circle represents a vaccinee with the color denoting the response group (blue: early-converter, yellow: late-converter, red: non-converter). (C) HBsAg-predictive ratio, $R_{h b s}$ when calculated on the memory CD4 TCR $\beta$ repertoires at day 60. (D) HBsAg-predictive ratio, $R_{h b s}$, when calculated on the memory CD4 TCR $\beta$ repertoires at day 0 . (E) Receiver operating characteristic $(\mathrm{ROC})$ curve using $R_{h b s}$ to differentiate between early-converters and late-converters in a leave-one-out cross-validation at day 0 . Reported is the area under the curve (AUC) and its $95 \%$ confidence interval. Data for B, C, D, and E are available in Figure 3-source data 1. (F) ROC curve using $R_{\text {hbs }}$ to differentiate between age-matched early-converters and late-converters in a leave-one-out cross-validation at day 0 . Age-matching was accomplished retaining only samples in the age range 40-55. A Wilcoxon test was used to confirm that there was no difference in age distributions between early- and late-converters ( $p$-value $=0.60$, mean $E C=44.5$ years, mean LC 45.1 years). Diagonal line denotes a random classifier. Reported is the area under the curve (AUC) and its $95 \%$ confidence interval.

The online version of this article includes the following source data and figure supplement(s) for figure 3 :

Source data 1. Hepatitis $\mathrm{B}$ surface antigen (HBsAg)-predictive ratio $\left(R_{\mathrm{hb}}\right)$ data.

Figure supplement 1. Overview of the outcome of in vitro expansion experiments.

\section{Vaccine-specific conventional and regulatory memory CD4 T cells induced in early-converters}

After showing evidence for the existence of vaccine-specific TCR $\beta$ sequences pre-vaccination and that individuals with a higher number of HBsAg peptide-specific clonotypes had earlier seroconversion, we attempted to link this observation to differences in vaccine-specific CD4 T cells responses using CD4 $T$ cell assays. As $T_{\text {REG }}$ cells might suppress vaccine-induced immune responses (Brezar et al., 2016), we used activation markers CD40L (CD154) and 4-1BB (CD137) to help delineate the conventional $\left(T_{C O N}\right)$ and regulatory $\left(T_{R E G}\right)$ phenotypes of activated CD4 $T$ cells. In this scheme, after $6 \mathrm{hr}$ of antigen stimulation, $C D 40 L^{+} 4-1 \mathrm{BB}^{-}$can be used as a signature for antigen-specific CD4 $\mathrm{T}_{\mathrm{CON}}$ cells, as opposed to $\mathrm{CD}_{40 \mathrm{~L}^{-}} 4-1 \mathrm{BB}^{+}$signature for antigen-specific CD4 $\mathrm{T}_{\mathrm{REG}}$ cells (Elias et al., 2020; Schoenbrunn et al., 2012). Additionally, we added CD25 and CD127 to better identify $T_{\text {REG }}$ cells (Liu et al., 2006; Seddiki et al., 2006) and CXCR5 to further distinguish circulatory $T$ follicular helper cells ( $\mathrm{CT}_{\mathrm{FH}}$ ) and circulatory $\mathrm{T}$ follicular regulatory cells ( $\mathrm{CT}_{\mathrm{FR}}$ ) (Bentebibel et al., 2011; Fonseca et al., 2017) (see Figure 4-figure supplement 1 for gating strategy).

Using the converse expression of CD40L and 4-1BB, CD40L ${ }^{+} 4-1 \mathrm{BB}^{-}$and $\mathrm{CD} 40 \mathrm{~L}^{-} 4-1 \mathrm{BB}^{+} \mathrm{CD} 4 \mathrm{~T}$ cells have a $C D 25^{\text {low }} C D 127^{\text {high }}$ and $C D 25^{\text {high }} \mathrm{CD} 127^{\text {low }}$ phenotype, respectively (Figure 4-figure supplement 2), and validate their use for the distinction of activated $T_{\text {CON }}$ and $T_{R E G}$ cells as described before (Schoenbrunn et al., 2012).

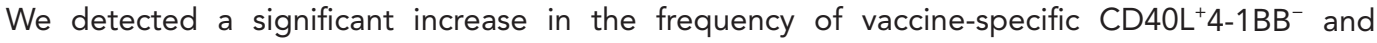

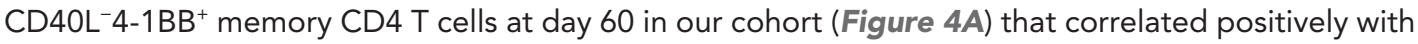
the increase in antibody titer between day 0 and day 365 (Figure 4B, Figure 4-figure supplement 3). Upon a closer look, the induction of both signatures of vaccine-specific memory CD4 T cells was only true for early-converters (Figure 4C, see Figure 4-figure supplement 4A for non-converters and Figure 4-figure supplement 4B for vaccine-specific CD4 T cells). Late-converters did not show a detectable memory CD4 T cell response. Although a subset of both early- and late-converters had detectable memory CD4 T cell responses prior to vaccination, we observed no significant differences in the frequencies of $\mathrm{CD}_{40 L^{+}} 4-1 \mathrm{BB}^{-}$and $\mathrm{CD} 40 \mathrm{~L}^{-} 4-1 \mathrm{BB}^{+}$memory $\mathrm{CD} 4 \mathrm{~T}$ cells between the two groups at day 0 (Figure 4D).

Collectively, flow cytometry data reveal that the expression of CD40L and 4-1BB in our ex vivo assay is consistent with our serological data and reflects the lack of seroconversion at day 60 in lateconverters. However, it does not support the existence of more vaccine-specific memory CD4 T cells in early-converters prior to vaccination.

\section{Predictive capacity of TCRß repertoire holds true for CD4 $\mathrm{T}_{\text {CON }}$ immune response}

Response groups used so far were established based on the dynamics of anti-HBs titers following vaccination. However, response groups can be defined based on the data of antigen specificity from the ex vivo CD4 T cell assay. Thus the frequency of $\mathrm{CD} 4 \mathrm{LL}^{+} 4-1 \mathrm{BB}^{-}$and $\mathrm{CD}^{-} \mathrm{LL}^{-} 4-1 \mathrm{BB}^{+}$memory $\mathrm{CD} 4$ $T$ cells were used to define a low and high response group at three different times points (days 60, 
A Vaccine-specific memory CD4 T cells over time
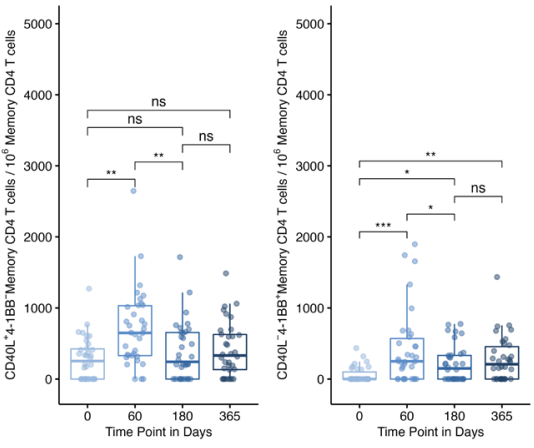

B

Correlation of vaccine-specific memory CD4 T cells at day 60 and antibody titer difference between day 365 and day 0

C

Vaccine-specific memory CD4 T cells over time for early and late-converters
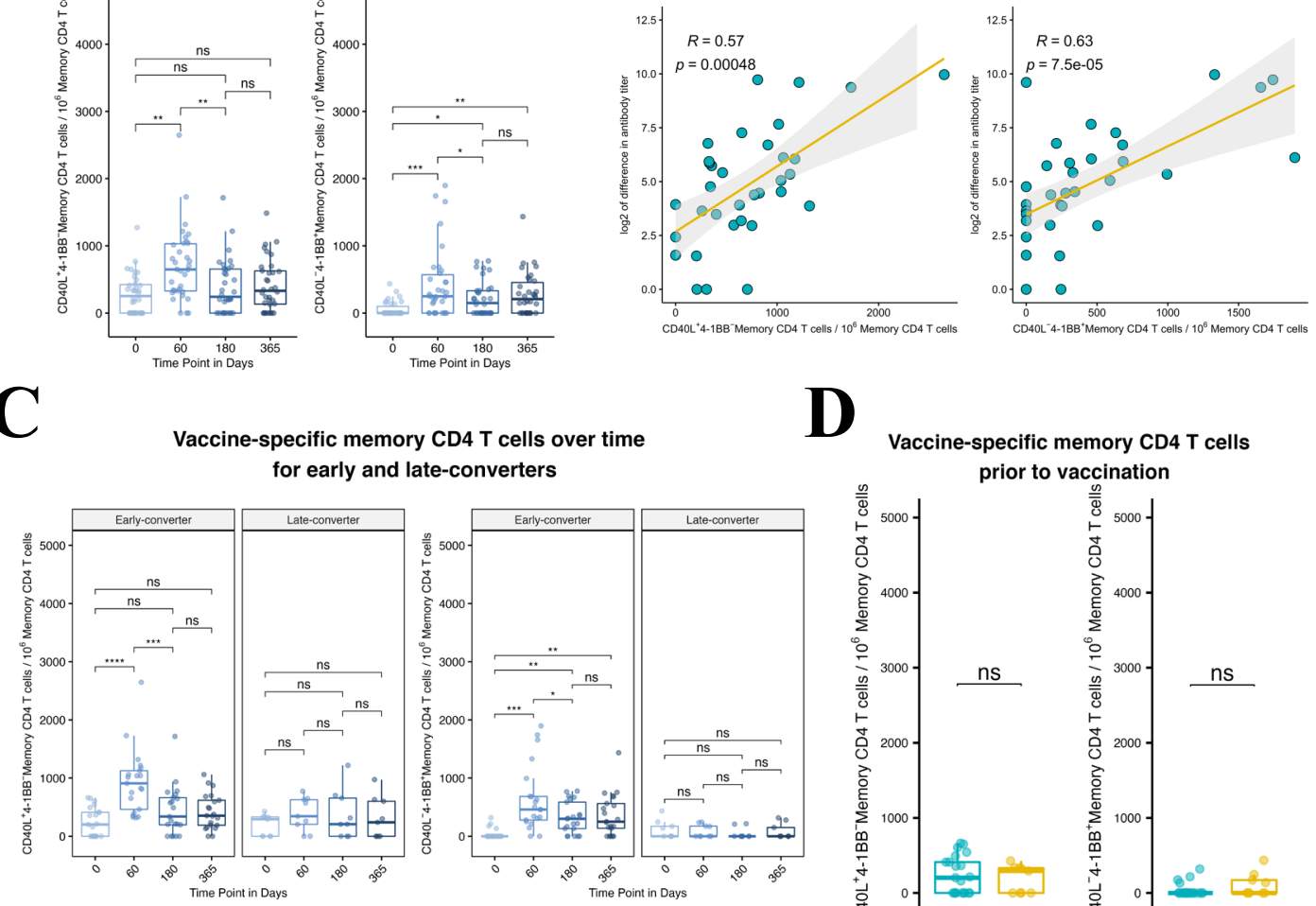

\section{D}

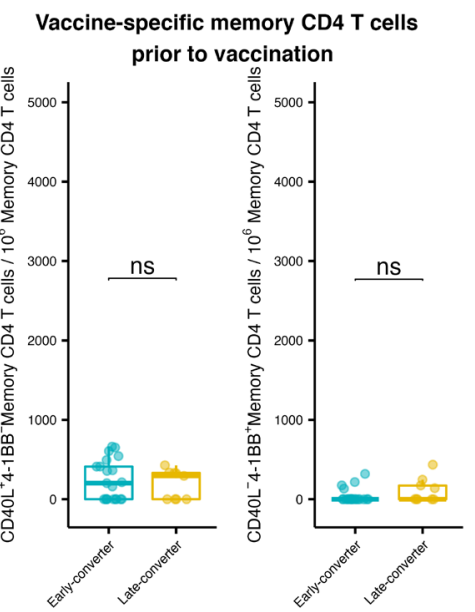

$\mathbf{E}$

ROC curve for $\mathbf{R}_{\text {hbs }}$ to predict frequency of vaccine-specific $\mathrm{CD}^{4} 0 \mathrm{~L}^{+} 4-1 \mathrm{BB}^{-}$ memory CD4 T cell

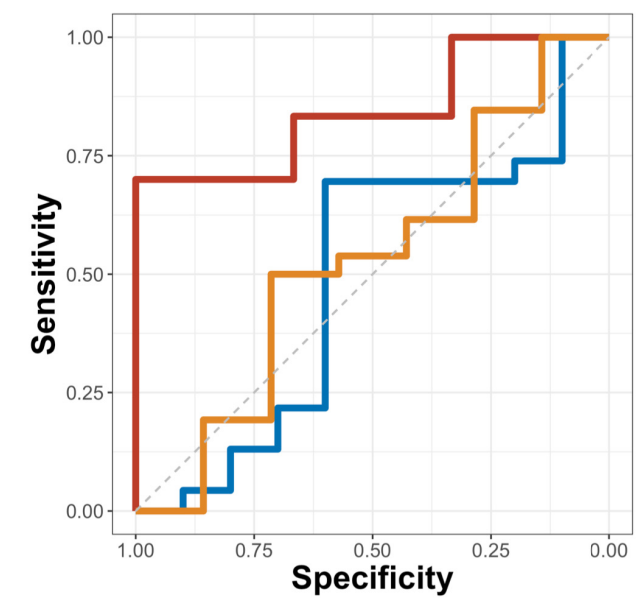

$\mathbf{F}$

ROC curve for $\mathbf{R}_{\text {hbs }}$ to predict frequency of vaccine-specific CD40L-4-1BB ${ }^{+}$ memory CD4 T cell

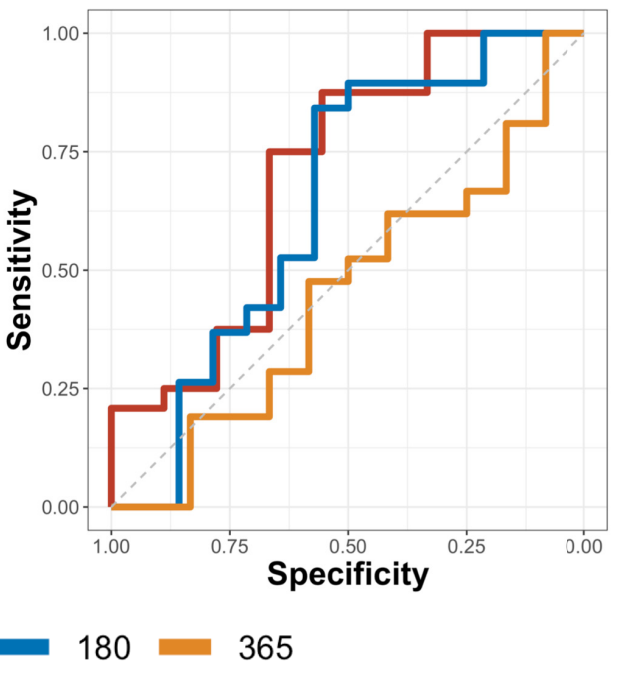

Time point $=30=180=365$

Figure 4. Hepatitis $B$ vaccine induces a vaccine-specific $C D 40 L^{+} 4-1 B^{-}$and $C D 40 L^{-} 4-1 B^{+}$memory $C D 4 T$ cell response in early-converter vaccinees. Peripheral blood mononuclear cells (PBMCs) from vaccinees were stimulated with $2 \mu \mathrm{g} / \mathrm{ml}$ of the master peptide pool (hepatitis $B$ surface antigen [HBsAg]) and assessed for converse expression of 4-1BB and CD40L by flow cytometry on days $0,60,180$, and 365 . Shown is number of vaccine-specific memory CD4 T cells out of $10^{6}$ memory CD4 T cells after subtraction of responses in negative control. (A) Aggregate analysis from vaccinees (including Figure 4 continued on next page 
Figure 4 continued

early-, late-, and non-converters) showing a peak of vaccine-specific CD40L ${ }^{+} 4-1 \mathrm{BB}^{-}$and $\mathrm{CD}^{4} \mathrm{LL}^{-} 4-1 \mathrm{BB}^{+}$memory CD4 T cell at day 60 (day 60 after first dose of the vaccine and day 30 after second dose), declining thereafter. Shown are numbers of vaccine-specific memory CD4 T cells out of $10^{6}$ memory CD4 T cells. (B) Correlation between the difference in antibody titer between day 365 and day 0 and vaccine-specific $\mathrm{CD}^{2} \mathrm{LL}^{+} 4-1 \mathrm{BB}^{-}$and $\mathrm{CD}^{-} 4 \mathrm{~L}^{-} 4-$ $1 \mathrm{BB}^{+}$memory CD4 T cell at day 60. (C) Aggregate analysis from early- and late-converter vaccinees showing a significant induction of vaccine-specific

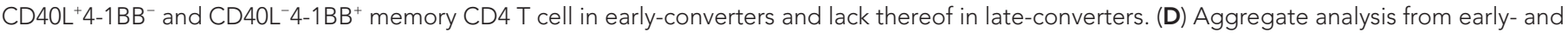

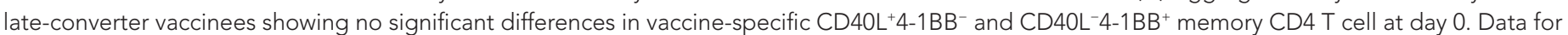
$\mathrm{A}, \mathrm{B}, \mathrm{C}$, and D are available in Figure 4-source data 1. (E) Receiver operating characteristic (ROC) curves for $R_{h b s}$ from day 0 data in a leave-one-out cross-validation compared to the frequency of vaccine-specific CD40L $4-1 \mathrm{BB}^{-}$memory CD4 T cell out of $10^{6}$ memory CD4 T cells for each vaccinee at time points 60 (area under the curve $[\mathrm{AUC}]=0.84$ ), 180 (AUC =0.56), and 365 (AUC =0.57). (F) Receiver operating characteristic (ROC) curves for $R_{h b s}$ from day 0 data in a leave-one-out cross-validation compared to the frequency of vaccine-specific $\mathrm{CD} 40 \mathrm{~L}^{-} 4-1 \mathrm{BB}^{+}$memory $\mathrm{CD}_{4} \mathrm{~T}$ cell out of $10^{6}$ memory CD4 T cells for each vaccinee at time points $60(A \cup C=0.62), 180(A \cup C=0.56)$, and $365(A \cup C=0.52)$. Statistical significance was indicated with ns $p>$ $0.05,{ }^{*} p \leq 0.05,{ }^{* \star} p \leq 0.01,{ }^{* \star *} p \leq 0.001,{ }^{* \star \star *} p \leq 0.0001$ rs, Spearman's correlation coefficient, $-1 \leq r s \leq 1$; rs and $p$-value by Spearman's correlation test.

The online version of this article includes the following source data and figure supplement(s) for figure 4:

Source data 1. Ex vivo T cell assay and serological data.

Figure supplement 1. Gating strategy of ex vivo T cell phenotyping of vaccine-specific T cells.

Figure supplement 2. $C D 40 L^{+} 4-1 \mathrm{BB}^{-}$and $C D 40 L^{-} 4-1 \mathrm{BB}^{+} \mathrm{CD} 4 \mathrm{~T}$ cells have a $T_{\mathrm{CON}}$ and $\mathrm{T}_{\mathrm{REG}}$ phenotype, respectively.

Figure supplement 3. Relationship between serological memory and memory CD4 $T$ cell response to the vaccine.

Figure supplement 4. Hepatitis B vaccine induces a vaccine-specific CD4 T cell response in early-converter vaccinees.

180, and 365). For each time point, the same $R_{\text {hbs }}$ metric was used in a leave-one-out cross-validation as before to differentiate between these novel response group definitions. Results indicate that the $R_{\text {hbs }}$ metric is a good predictor for HBsAg-specific memory CD4 T cells with a $\mathrm{T}_{\text {Con }}$ signature (but not $\mathrm{T}_{\mathrm{REG}}$ signature) identified at day 60 post-vaccination (Figure 4E and F). However, the classifier is less performant for the prediction of CD4 T cell response at later time points.

\section{An expanded subset of 4-1BB ${ }^{+}$CD45RA ${ }^{-} T_{R E G}$ cells is a prominent feature of late-converters}

In order to detect any distinct signatures of early- and late-converters, we analyzed pre-vaccination flow cytometry data to examine major CD4 T cell subsets: $T_{H}, T_{R E G}, c T_{F H}$, and $c T_{F R}$ cells.

Using manual gating in which regulatory $T$ cells $\left(T_{R E G}\right)$ were defined as viable $C D 3^{+} C D 4^{+} C D 8^{-} \mathrm{C}$ $\mathrm{D} 25^{+} \mathrm{CD} 127^{-} \mathrm{CXCR5}^{-}$and were further divided into CD45RA ${ }^{+}$and CD45RA ${ }^{-} \mathrm{T}_{\mathrm{REG}}$ cells, we identified a significantly higher frequency of $4-1 B^{+} C D 45 R A^{-} T_{R E G}$ cells in late-converters compared to earlyconverters (Figure 5A and Figure 5-figure supplement 1).

$T_{R E G}$ cells showed higher 4-1BB expression compared to $T_{H}, c T_{F H}$, and $c T_{F R}$ cells (Figure 5B) and within $T_{R E G}$ subset, CD45RA ${ }^{-} T_{R E G}$ cells showed significantly higher expression of 4-1BB, accompanied with a higher expression of CD25, compared to CD45RA $\mathrm{T}_{\mathrm{REG}}$ cells (Figure $5 \mathrm{C}$ ). In this scheme, CD45RA ${ }^{-} T_{\text {REG }}$ can be divided into $4-1 B^{+} C D 25^{\text {high }}$ and $4-1 B^{-} C D 25^{\text {int }}$ subsets. It is worth noting here that no differences were detected in the frequency of CD45RA ${ }^{-}$or CD45RA ${ }^{+} T_{\text {REG }}$ cells within CD4 T cell compartment between the two groups (Figure 5D), and that it is the composition of $\mathrm{T}_{\mathrm{REG}}$ compartment that is distinct between the two groups (Figure 5E).

In summary, an expanded subset of $4-1 B^{+} C D 45 R A^{-} T_{R E G}$ cells pre-vaccination is a prominent feature of a delayed and modest immune response to HB vaccine in our cohort.

\section{Discussion}

In this study, we used high-throughput TCR $\beta$ repertoire profiling and ex vivo T cell assays to characterize memory CD4 T cell repertoires before and after immunization with HB vaccine, an adjuvanted subunit vaccine, and tracked vaccine-specific TCR $\beta$ clonotypes over two time points. As antigen-naïve adults were found to have an unexpected abundance of memory-phenotype CD4 T cells specific to viral antigens (Su and Davis, 2013; Su et al., 2013), we sought to investigate the influence that preexisting memory CD4 T cells can have on vaccine-induced immunity.

Commercially available HBV vaccines produce a robust and long-lasting anti-HBs response, and protection is provided by induction of an anti-HBs (antibody against HBV surface antigen) titer higher than $10 \mathrm{mlU} / \mathrm{ml}$ after a complete immunization schedule of three doses (Meireles et al., 2015). 


\section{A \\ B \\ C}

Frequency before vaccination

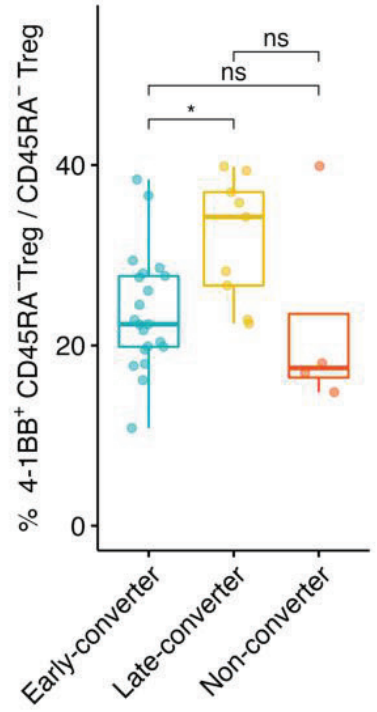

4-1BB expression on CD4 T cell subsets

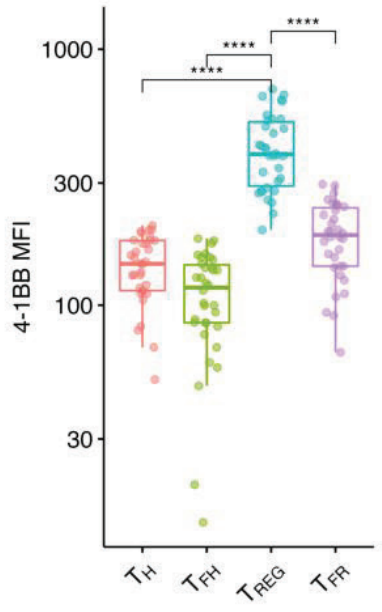

CD25 and 4-1BB expression in $T_{\text {REG }}$ cell subsets

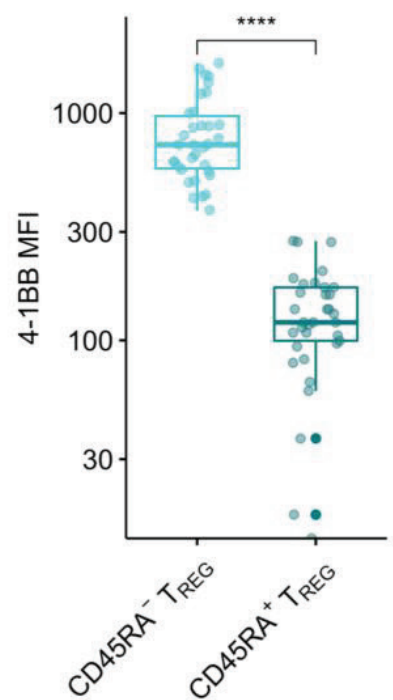

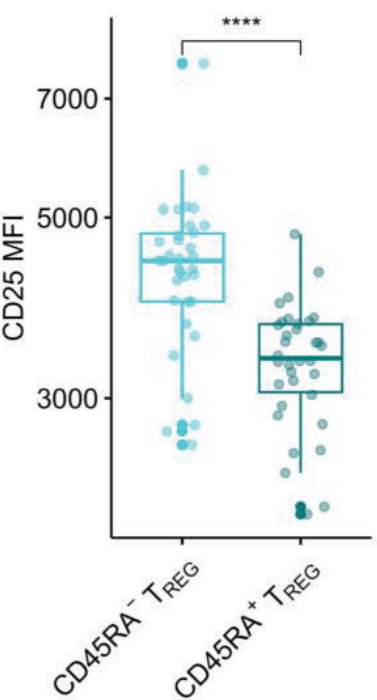

D

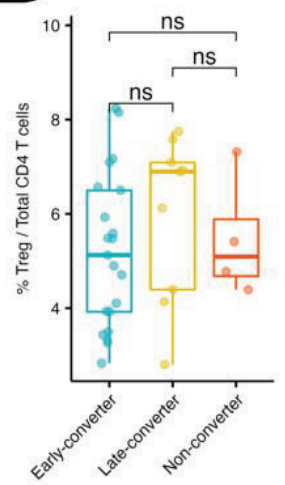

Frequency of $\mathrm{T}_{\mathrm{REG}}$ cells in total CD4 T cells

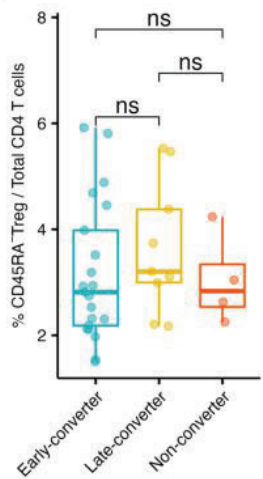

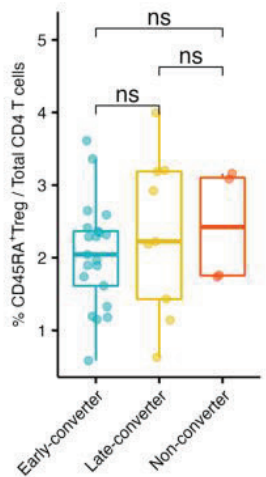

$\mathbf{E}$

Subsets of $T_{\text {REG }}$ cells by CD45RA and 4-1BB

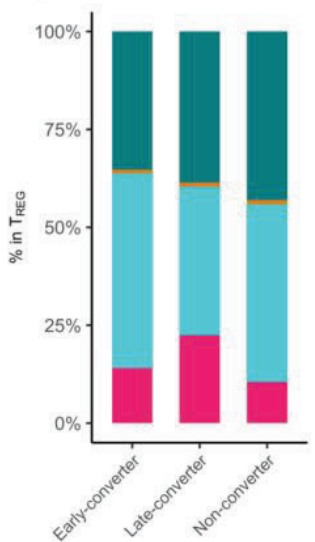

Figure 5. An expanded 4-1BB ${ }^{+} C D 45 R A^{-} T_{R E G}$ cells within $T_{R E G}$ compartment is a prominent feature in late-converters prior to vaccination. Peripheral blood mononuclear cells (PBMCs) from vaccinees at day 0 (prior to vaccination) were phenotyped for expression of markers of $\mathrm{T}_{\text {REG }}$. (A) Aggregate analysis of 4-1BB ${ }^{+} C D 45 R A^{-} T_{R E G}$ within CD45RA- $T_{R E G} C D 4 T$ cells in early- and late- and non-converter vaccinees before vaccination. (B) Aggregate analysis of the median fluorescence intensity of $4-1 B B$ in $T_{H}, C T_{F H}, T_{R E G}$, and $c T_{F R}$ cells before vaccination. (C) Aggregate analysis of the median fluorescence intensity of 4-1BB (left panel) and CD25 (right panel) in CD45RA ${ }^{-} T_{R E G}$ and CD45RA ${ }^{+} T_{R E G}$ cells before vaccination. Data for A, B, and C are available in Figure 5-source data 1. (D) Frequency of $T_{R E G}, C D 45 R A^{-} T_{R E G}$, and CD45RA ${ }^{+} T_{R E G}$ cells within total CD4 $T$ cells in early-, late-, and nonconverter vaccinees before vaccination. (E) Composition of $T_{\text {REG }}$ compartment as determined by expression of 4-1BB and CD45RA in early-, late-, and non-converter vaccinees before vaccination. Statistical significance was indicated with $n s p>0.05,{ }^{*} p \leq 0.05,{ }^{* *} p \leq 0.01,{ }^{* \star *} p \leq 0.001,{ }^{* \star * *} p \leq 0.0001$.

The online version of this article includes the following source data and figure supplement(s) for figure 5 :

Source data 1. Frequency of $4-1 \mathrm{BB}^{+} \mathrm{CD} 45 \mathrm{RA}^{-} \mathrm{T}_{\mathrm{REG}}$ cells and median fluorescence intensity data.

Figure supplement 1. An expanded 4-1BB+ ${ }^{+} C D 45 R A^{-} T_{R E G}$ cells within $T_{R E G}$ compartment is a prominent feature in late-converters prior to vaccination. 
However, $5-10 \%$ of healthy adult vaccinees fail to produce protective titers of anti-HBs and can be classified as non-responders (Meireles et al., 2015). In our cohort, 13 vaccinees did not seroconvert by day 60 (30 days following administration of the second vaccine dose), as determined by antibody titer. Out of this group, nine vaccinees seroconverted by day 180 or day 365 , referred to here as lateconverters, and four vaccinees did not seroconvert, referred to here as non-converters.

A hallmark of adaptive immunity is a potential for memory immune responses to increase in both magnitude and quality upon repeated exposure to the antigen (Sallusto et al., 2010). Our systems immunology data supports the theory that preexisting memory CD4 T cell TCR $\beta$ sequences specific to $\mathrm{HBsAg}$, the antigenic component of the current $\mathrm{HB}$ vaccine, predict which individuals will mount an early and more vigorous immune response to the vaccine as evidenced by a higher fold change in anti-HBs antibody titer and a more significant induction of antigen-specific CD4 T cells. It is postulated that preexisting memory CD4 T cell clonotypes are generated due to the highly degenerate nature of $\mathrm{T}$ cell recognition of antigen/MHC and are cross-reactive to environmental antigens (Sewell, 2012). For example, preexisting memory CD4 T cells are well-established in unexposed HIV-seronegative individuals, although at a significantly lower magnitude than HIV-exposed seronegative individuals (Campion et al., 2014; Ritchie et al., 2011), and were likely primed by exposure to environmental triggers or the human microbiome.

We and others have shown before that the TCR $\beta$ repertoire of CD4 T cells encodes the antigen exposure history of each individual and that antigen-specific TCR $\beta$ sequences could serve to automatically annotate the infection or exposure history (DeWitt et al., 2018; Emerson et al., 2017; De Neuter et al., 2019). In this study, we show that similar principles can be used to study vaccine responsiveness. Specifically, the recruitment of novel vaccine-specific $T$ cell clonotypes into memory compartment following vaccination can be tracked by examining the CD4 memory TCR $\beta$ repertoire over time. While we observed no increase in the frequency of the vaccine-specific memory $T$ cells, as the time point may have missed the peak of the clonal expansion of effector CD4 T cells as was reported before (Blom et al., 2013; Kohler et al., 2012; Pogorelyy et al., 2018), a significant rise in the number of unique vaccine-specific T cell clonotypes was detected. This observation is consistent with earlier studies of $T$ cell immune repertoire that showed that antigen-specific TCR $\beta$ sequences do not always overlap with those sequences that increase in frequency after infection or vaccination (DeWitt et al., 2015). More interestingly, individuals with the earlier and more robust response against the vaccine had a telltale antigen-specific signature in their memory TCR $\beta$ repertoire prior to vaccination, despite the lack of HBsAg antibodies and prior vaccination history.

Detection of this vaccine-specific signature was possible due to the development of a novel predictive model that used epitope-specific TCR $\beta$ sequences from one set of individuals to make predictions about another. This is a non-trivial task as the MHC class II molecules vary between vaccinees, which in turn allows for great variation of the presented epitopes. However, we were able to cover the entire HBsAg and obtained a sufficient sample size to likely cover the most immunoprevalent epitopes. It can be presumed that we do not capture the full HBsAg T cell response, but obtain enough sequences which are representative for the response as a whole. In addition, a correction factor was needed to account for the occurrence of bystander-activated T cells within the original epitope-specific TCR $\beta$ sequences. Indeed, in those vaccinees without an early seroconversion (at day 60), putative vaccinespecific $T$ cells might be induced due to bystander activation. This was supported by predictions using the TCRex tool (Gielis et al., 2019), which matched these TCR sequences to common viral or other epitopes. It is of note that these TCR $\beta$ sequences are matched with CD8 T cell epitopes, while they originate from isolated CD4 T cells. This is likely due to the great similarity between the TCR $\beta$ sequences of CD4 and CD8 T cells as noted in prior research (De Neuter et al., 2018).

However, our in vitro antigen-specific data, using an assay that enables discrimination of $\mathrm{T}_{\mathrm{CON}}$ and $T_{R E G}$ cells using the converse expression of the activation markers CD40L and 4-1BB (Frentsch et al., 2005; Schoenbrunn et al., 2012), failed to show a significant difference in preexisting antigen-specific CD4 T cells between early- and late-converters prior to vaccine administration. It is plausible that our activation proteins, CD40L and 4-1BB, might be unsuitable to detect preexisting memory CD4 T cells but this is unlikely as both proteins were used successfully in similar studies (Bacher et al., 2014a; Bacher et al., 2014b).

Another plausible explanation is that the signal is below the detection limit of the assay and that more sensitive techniques that require pre-enrichment of $\mathrm{CD} 4 \mathrm{~L}^{+}$and $4-1 \mathrm{BB}^{+} \mathrm{T}$ cells (using magnetic 
beads) (Bacher et al., 2013) or cultured ELISpot assay (Reece et al., 2004) are needed to capture preexisting vaccine-specific memory CD4 T cells directly from human peripheral blood. A similar disagreement between $B$ cell receptor clonotype diversity underlying vaccine-induced response and a conventional B cell ELISpot assay was reported before following HB vaccination (Galson et al., 2016).

$\mathrm{T}_{\text {REG }}$ cells represent about $5-10 \%$ of human CD4 T cell compartment and are identified by the constitutive surface expression of CD25, also known as IL-2 receptor $\alpha$ subunit (IL-2Ra), and the nuclear expression of forkhead family transcription factor 3 (Foxp3), a lineage specification factor of $T_{\text {REG }}$ cells (Rudensky, 2011). Regulatory memory T cells play a role in the mitigation of tissue damage induced by effector memory $T$ cells during protective immune responses, resulting in a selective advantage against pathogen-induced immunopathology (Garner-Spitzer et al., 2013; Lanteri et al., 2009; Lin et al., 2018; Lovelace and Maecker, 2018). Several studies have identified CD4 $T_{\text {REG }}$ cells with specificity to pathogen-derived peptides in murine models and showed evidence for an induced expansion of $T_{R E G}$ cells followed by an emergence and a long-term persistence of $T_{\text {REG }}$ cells with a memory phenotype and potent immunosuppressive properties (Lin et al., 2018; Sanchez et al., 2012). Blom et al. reported a significant and transient activation of $T_{\text {REG }}$ cells (identified by upregulation of CD38 and Ki67) in humans 10 days after administration of live attenuated yellow fever virus 17D vaccine (Blom et al., 2013). The induction of vaccine-specific $T_{\text {REG }}$ cells in our cohort is unexpected and the role it might play in vaccine-induced immunity warrants further investigation.

The association of an expanded $4-1 \mathrm{BB}^{+} \mathrm{CD} 45 \mathrm{RA}^{-} \mathrm{T}_{\mathrm{REG}}$ subset with a delayed immune response to $\mathrm{HB}$ vaccine was not described before. Miyara et al. showed that blood contains two distinct subsets of stable and suppressive $T_{\text {REG }}$ cells: resting $T_{R E G}$, identified as FOXP3 ${ }^{\text {low } C D 45 R A}{ }^{+}$CD4 $T$ cells, and activated $T_{R E G}$, identified as FOXP3 ${ }^{\text {high }}$ CD45RA- CD4 $T$ cells. They further noted that activated $T_{\text {REG }}$ cells constitute a minority subset within cord blood $\mathrm{T}_{\mathrm{REG}}$ cells and increase gradually with age (Miyara et al., 2009). As activated $T_{\text {REG }}$ cells were shown to have an increased expression of proteins indicative of activation, including ICOS and HLA-DR (Booth et al., 2010; Ito et al., 2008; Mason et al., 2015; Miyara et al., 2009; Mohr et al., 2018), it might be the case that an upregulation of 4-1BB is one more feature of this population or a subset thereof. Moreover, $T_{R E G}$ cells in mice were shown to modulate $T_{F H}$ formation and germinal center $(G C) B$ cell responses and to diminish antibody production in a CTLA-4 mediated suppression (Wing et al., 2014). Interestingly, CD45RA- $T_{\text {REG }}$ cells were shown to be more rich in preformed CTLA-4 stored in intracellular vesicles compared to CD45RA ${ }^{+} T_{\text {REG }}$ cells (Miyara et al., 2009).

4-1BB was shown to be constitutively expressed by $T_{\text {REG }}$ cells (McHugh et al., 2002) and that 4-1BB $\mathrm{B}_{\mathrm{REG}}$ cells are functionally superior to $4-1 \mathrm{BB}^{-} \mathrm{T}_{\mathrm{REG}}$ cells in both contact-dependent and contactindependent immunosuppression (Kachapati et al., 2012). 4-1BB ${ }^{+} \mathrm{T}_{\mathrm{REG}}$ cells are the major producers of the alternatively spliced and soluble isoform of 4-1BB among T cells (Kachapati et al., 2012). 4-1BB was shown before to be preferentially expressed on $T_{R E G}$ cells compared with other non-regulatory CD4 T cell subsets (McHugh et al., 2002) and that 4-1BB-costimualtion induces the expansion of $T_{\text {REG }}$ cells both in vitro and in vivo (Zheng et al., 2004). Moreover, agonistic anti-4-1BB mAbs have been shown to abrogate T cell-dependent antibody responses in vivo (Mittler et al., 1999) and to ameliorate experimental autoimmune encephalomyelitis by skewing the balance against $T_{H} 17$ differentiation in favor of $T_{R E G}$ differentiation (Kim et al., 2011). It is plausible that the expansion 4-1BB ${ }^{+} C D 45 R A^{-} T_{R E G}$ cells in late-converters is involved in the suppression of GC vaccine-specific $T_{F H}$ cells and the ensuing antibody response in our cohort, but this remains speculative and further research is warranted.

It is enticing to speculate that the preexisting memory CD4 T cells result from the complex interplay between cellular immunity and the human microbiome. A role for the microbiota in modulating immunity to viral infection was suggested in 1960s (Robinson and Pfeiffer, 2014), and since then we gained better understanding of the impact of the various components of the microbiota including bacteria, fungi, protozoa, archaea, and viruses on the murine and human immune systems (Winkler and Thackray, 2019).

Viral clearance of HB virus infection depends on the age of exposure and neonates and young children are less likely to spontaneously clear the virus (Yuen et al., 2018). Han-Hsuan et al. have shown evidence in mice that this age dependency is mediated by gut microbiota that prepare the liver immunity system to clear HBV, possibly via a TLR4 signaling pathway (Chou et al., 2015). In this study, young mice that have not reached an equilibrium in the gut microbiota exhibited prolonged $\mathrm{HBsAg}$ persistence, impaired anti-HBs antibody production, and limited Hepatitis B core antigen 
(HBcAg)-specific IFN $\gamma^{+}$splenocytes. More recently, Tingxin et al. provided evidence for a critical role of the commensal microbiota in supporting the differentiation of GC B cells, through follicular Thelper $\left(T_{F H}\right)$ cells, to promote the anti-HBV humoral immunity (Wu et alo, 2019).

Our study bears some intrinsic limitations. A major drawback is the restricted number of days at which TCR $\beta$ repertoire was profiled, as vaccine-specific perturbations within the repertoire may occur at different time points for early-, late-, and non-converters. Additionally, more in-depth characterization and functional studies on $4-1 \mathrm{BB}^{+} \mathrm{CD} 45 \mathrm{RA}^{-} \mathrm{T}_{\mathrm{REG}}$ cells could have helped shed more light on the role they play in vaccine-induced immunity. Future studies in larger cohorts and with a more comprehensive TCR $\beta$ repertoire profiling and CD4 T cells immunophenotyping are required to validate our findings.

In conclusion, our analysis of the memory CD4 T cell repertoire has uncovered a role for preexisting memory CD4 T cells in naïve individuals in mounting an earlier and more vigorous immune response to $H B$ vaccine and argue for the utility of pre-vaccination TCR $\beta$ repertoire in the prediction of vaccineinduced immunity. Moreover, we identify a subset of $4-1 \mathrm{BB}^{+}$memory $\mathrm{T}_{\mathrm{REG}}$ cells that is expanded in individuals with delayed immune response to the vaccine, which might further explain the heterogeneity of response to $\mathrm{HB}$ vaccine.

Key resources table

\section{Materials and methods}

\begin{tabular}{|c|c|c|c|c|}
\hline $\begin{array}{l}\text { Reagent type (species) } \\
\text { or resource }\end{array}$ & Designation & Source or reference & Identifiers & Additional information \\
\hline Antibody & CD3-BV510 (SK7) (mouse monoclonal) & BioLegend & Cat\# 344828 & FACS (1/20 per test) \\
\hline Antibody & CD3-PerCP (BW264/56) (mouse monoclonal) & Miltenyi Biotec & Cat\# 130-113-131 & FACS (1/50 per test) \\
\hline Antibody & $\begin{array}{l}\text { CD4-APC (REA623) (recombinant antibodies, } \\
\text { REAfinity) }\end{array}$ & Miltenyi Biotec & Cat\# 130-113-222 & FACS (1/50 per test) \\
\hline Antibody & CD4-APC (RPA-T4) (mouse monoclonal) & BD Biosciences & Cat\# 555349 & FACS (1/5 per test) \\
\hline Antibody & $\begin{array}{l}\text { CD4-PerCP/Cy5.5 (RPA-T4) (mouse } \\
\text { monoclonal) }\end{array}$ & BioLegend & Cat\# 300530 & FACS (1/20 per test) \\
\hline Antibody & $\begin{array}{l}\text { CD8-VioGreen (REA734) (recombinant } \\
\text { antibodies, REAfinity) }\end{array}$ & Miltenyi Biotec & Cat\# 130-110-684 & FACS (1/50 per test) \\
\hline Antibody & $\begin{array}{l}\text { CD8-Pacific Orange (3B5) (mouse } \\
\text { monoclonal) }\end{array}$ & Invitrogen & Cat\# MHCD0830 & FACS (1/20 per test) \\
\hline Antibody & CD8-APC/Cy7 (SK1) (mouse monoclonal) & BioLegend & Cat\# 344714 & FACS (1/20 per test) \\
\hline Antibody & CD40L-PE (5C8) (mouse monoclonal) & Miltenyi Biotec & Cat\# 130-092-289 & FACS (1/10 per test) \\
\hline Antibody & $\begin{array}{l}\text { CXCR5-PE-Cy7 (MU5UBEE) (mouse } \\
\text { monoclonal) }\end{array}$ & eBioscience & Cat\# 25-9185-42 & FACS $(7 / 100$ per test $)$ \\
\hline Antibody & CD45RA-AF488 (HI100) (mouse monoclonal) & BioLegend & Cat\# 304114 & FACS (1/20 per test) \\
\hline Antibody & CD45RO-PE (UCHT1) (mouse monoclonal) & BD Biosciences & Cat\# 555493 & FACS (1/5 per test) \\
\hline Antibody & CD25-BV421 (M-A251) (mouse monoclonal) & BioLegend & Cat\# 356114 & FACS (1/20 per test) \\
\hline Antibody & CD127-BV785 (A019D5) (mouse monoclonal) & BioLegend & Cat\# 351330 & FACS (1/20 per test) \\
\hline Antibody & CD137-PE (4B4-1) (mouse monoclonal) & BioLegend & Cat\# 309804 & FACS (1/20 per test) \\
\hline Antibody & CD154-APC (5C8) (mouse monoclonal) & Miltenyi Biotec & Cat\# 130-113-603 & FACS (3/100 per test) \\
\hline Antibody & Anti-CD40 (HB14) (mouse monoclonal) & Miltenyi Biotec & Cat\# 130-094-133 & Assay $(1 \mu \mathrm{g} / \mathrm{ml})$ \\
\hline Antibody & Anti-CD28 (CD28.2) (mouse monoclonal) & BD Biosciences & Cat\# 556620 & Assay $(1 \mu \mathrm{g} / \mathrm{ml})$ \\
\hline $\begin{array}{l}\text { Peptide, recombinant } \\
\text { protein }\end{array}$ & Single peptides of $\mathrm{HBsAg}$ & JPT Peptide Technologies & Customized & 54 single peptides \\
\hline $\begin{array}{l}\text { Peptide, recombinant } \\
\text { protein }\end{array}$ & Peptide matrix pools of $\mathrm{HBsAg}$ & JPT Peptide Technologies & Customized & $\begin{array}{l}\text { A set of } 15 \text { matrix pools each with } \\
7-8 \text { peptides }\end{array}$ \\
\hline $\begin{array}{l}\text { Peptide, recombinant } \\
\text { protein }\end{array}$ & Master peptide pool of $\mathrm{HBsAg}$ & JPT Peptide Technologies & Customized & A pool of 54 single peptides \\
\hline
\end{tabular}

Continued on next page 


\section{Continued}

\begin{tabular}{|c|c|c|c|c|}
\hline $\begin{array}{l}\text { Reagent type (species) } \\
\text { or resource }\end{array}$ & Designation & Source or reference & Identifiers & Additional information \\
\hline $\begin{array}{l}\text { Commercial assay } \\
\text { or kit }\end{array}$ & CD4 MicroBeads & Miltenyi Biotec & Cat\# 130-045-101 & \\
\hline $\begin{array}{l}\text { Commercial assay } \\
\text { or kit }\end{array}$ & DNA/RNA Shield & Zymo Research & Cat\# R1100-50 & \\
\hline $\begin{array}{l}\text { Commercial assay } \\
\text { or kit }\end{array}$ & Quick-DNA Microprep kit & Zymo Research & Cat\# D3020 & \\
\hline $\begin{array}{l}\text { Commercial assay } \\
\text { or kit }\end{array}$ & ImmunoSEO hsTCRB sequencing kit & Adaptive Biotechnologies & & \\
\hline $\begin{array}{l}\text { Commercial assay } \\
\text { or kit }\end{array}$ & Quick-RNA Microprep kit & Zymo Research & Cat\# R1050 & \\
\hline $\begin{array}{l}\text { Commercial assay } \\
\text { or kit }\end{array}$ & QIAseq Immune Repertoire RNA Library kit & Qiagen & Cat\# 333705 & \\
\hline $\begin{array}{l}\text { Commercial assay } \\
\text { or kit }\end{array}$ & Qubit dsDNA HS Assay & Thermo Fisher Scientific & Cat\# Q32854 & \\
\hline Software, algorithm & FlowJo version 10.5 .3 & Tree Star & RRID:SCR_002865 & \\
\hline Software, algorithm & immunoSEQ analyzer (v2) & Adaptive Biotechnologies & & \\
\hline Software, algorithm & TCRex web-based & $\begin{array}{l}\text { (Gielis et al., 2019), https://tcrex. } \\
\text { biodatamining.be/) }\end{array}$ & & \\
\hline Software, algorithm & $\mathrm{R}$ & https://www.r-project.org & RRID:SCR_001905 & \\
\hline Software, algorithm & RStudio & http://www.rstudio.com/ & RRID:SCR_000432 & \\
\hline Software, algorithm & ggplot2 (V3.3.2) & $\begin{array}{l}\text { (Wickham, 2016) https://ggplot2.tidyverse. } \\
\text { org/ }\end{array}$ & RRID:SCR_014601 & \\
\hline Software, algorithm & ggpubr (V0.2.5) & $\begin{array}{l}\text { https://CRAN.R-project.org/package= } \\
\text { ggpubr }\end{array}$ & RRID:SCR_021139 & \\
\hline Software, algorithm & rstatix (0.7.0) & https://CRAN.R-project.org/package=rstatix & RRID:SCR_021240 & \\
\hline Other & Sytox blue & Invitrogen & Cat\# S34857 & FACS (1/500 per test) \\
\hline Other & Fixable viability dye Zombie NIR & BioLegend & Cat\# 423106 & FACS (1/50 per test) \\
\hline Other & Carboxyfluorescein succinimidyl ester (CFSE) & Invitrogen & Cat\# C34554 & $2 \mu \mathrm{M}$ staining solution \\
\hline Other & Engerix-B & GlaxoSmithKline & & $20 \mu \mathrm{g}$ \\
\hline Other & Varicella zoster virus (VZV) lysate & Microbix Biosystem & Cat\# EL-03-02 & Viral lysate, assay $(4 \mu \mathrm{g} / \mathrm{m}$ \\
\hline
\end{tabular}

\section{Human study design and clinical samples}

A total of 34 healthy individuals (20-29 years: $10,30-39$ years: $7,40-49$ years: $16,50+$ years: 1 ) without a history of HBV infection or previous HB vaccination were recruited in this study after obtaining written informed consent. Individuals were vaccinated with an HB vaccine by intramuscular (m. deltoideus) injection (Engerix-B containing $20 \mu \mathrm{g}$ dose of alum-adjuvanted $\mathrm{HBsAg}$, GlaxoSmithKline) on days 0 and 30 (and on day 365). At days 0 (pre-vaccination), 60, 180, and 365 (Figure 1A), peripheral blood samples were collected on spray-coated lithium heparin tubes, spray-coated K2EDTA (dipotassium ethylenediamine tetra-acetic acid) tubes, and serum tubes (Becton Dickinson, NJ).

\section{Peripheral blood mononuclear cells}

Peripheral blood mononuclear cells (PBMCs) were isolated by Ficoll-Paque Plus gradient separation (GE Healthcare, Chicago, IL). Cells were stored in 10\% dimethyl sulfoxide in fetal bovine serum (Thermo Fisher Scientific, Waltham, MA). After thawing and washing cryopreserved PBMC, cells were cultured in AIM-V medium that contained L-glutamine, streptomycin sulfate at $50 \mu \mathrm{g} / \mathrm{ml}$, and gentamicin sulfate at $10 \mu \mathrm{g} / \mathrm{ml}$ (Thermo Fisher Scientific, Waltham, MA) and supplemented with $5 \%$ human serum (One Lambda, Canoga Park, CA).

\section{Serology and complete blood count}

Serum was separated and stored immediately at $-80^{\circ} \mathrm{C}$ until time of analysis. Anti-HBs antibody was titrated in serum from day 0, 60, 180, and 365 using Roche Elecsys Anti-HBs antibody assay on an 
Elecsys 2010 analyzer (Roche, Basel, Switzerland). An anti-HBs titer above $10 \mathrm{IU} / \mathrm{ml}$ was considered protective (Keating and Noble, 2003).

Serum IgG antibodies to CMV, EBV viral-capsid antigen, and HSV-1 and -2 were determined using commercially available sandwich ELISA kits in accordance with the manufacturer's instructions.

A complete blood count including leukocyte differential was run on a hematology analyzer (ABX MICROS 60, Horiba, Kyoto, Japan).

\section{Sorting of memory CD4 T cells}

Total CD4 T cells were isolated by positive selection using CD4 magnetic microbeads (Miltenyi Biotech, Bergisch Gladbach, Germany). Memory CD4 T cells were sorted after gating on single viable $\mathrm{CD}^{+} \mathrm{C}$ $\mathrm{D} 4^{+} \mathrm{CD} 8^{-} \mathrm{CD} 45 \mathrm{RO}^{+}$cells. The following fluorochrome-labeled monoclonal antibodies were used for staining: CD3-PerCP (BW264/56) (Miltenyi Biotech), CD4-APC (RPA-T4), and CD45RO-PE (UCHT1) (both from Becton Dickinson, Franklin Lakes, NJ) and CD8-Pacific Orange (3B5) (from Thermo Fisher Scientific, Waltham, MA). Cells were stained at room temperature for $20 \mathrm{~min}$ and sorted with FACSAria II (Becton Dickinson, Franklin Lakes, NJ). Sytox blue (Thermo Fisher Scientific, Waltham, MA) was used to exclude non-viable cells.

\section{Single peptides, peptide matrix pools, and epitope mapping}

A set of 15-mers peptides with an 11-amino acid overlap spanning the 226 amino acids along the small S protein of HBsAg, also designated as small HBs (Shouval, 2003), were synthesized by JPT Peptide Technologies (Berlin, Germany). The set, composed of 54 single peptides (see Supplementary file 1), was used in a matrix-based strategy to map epitopes against which the immune response is directed as described before (Precopio et al., 2008). The matrix layout enables efficient identification of epitopes within the antigen using a minimal number of cells. For this purpose, a matrix of 15 pools, 7 rows, and 8 columns, referred to as peptide matrix, was designed so that each peptide is in exactly one row-pool and one column-pool, thereby allowing for the identification of positive peptides at the intersection of positive pools. Matrix pools that induced a CD4 T cell response (as determined by CD40L/CD154 assay described below) which meets the threshold criteria for a positive response were considered in the deconvolution process. Top six single peptides were considered for peptide-specific T cell expansion and sorting. A master peptide pool is composed of all of the 54 single peptides and was used to identify and sort total vaccine-specific CD4 T cells. Each peptide was used at a final concentration of $2 \mu \mathrm{g} / \mathrm{ml}$. VZV lysate was purchased from Microbix Biosystem (Mississauga, Canada).

\section{Ex vivo $T$ cell stimulation (CD40L/CD154 assay)}

Thawed PBMCs from each vaccinee were cultured in AIM-V medium that contained L-glutamine, streptomycin sulfate at $50 \mu \mathrm{g} / \mathrm{ml}$, and gentamicin sulfate at $10 \mu \mathrm{g} / \mathrm{ml}$ (GIBCO, Grand Island, NY) and supplemented with $5 \%$ human serum (One Lambda, Canoga Park, CA). Cells were stimulated for $6 \mathrm{hr}$ with $2 \mu \mathrm{g} / \mathrm{ml}$ of each of the 15 peptide matrix pools in the presence of $1 \mu \mathrm{g} / \mathrm{ml}$ anti-CD40 antibody (HB14) (purchased from Miltenyi Biotec, Bergisch Gladbach, Germany) and $1 \mu \mathrm{g} / \mathrm{ml}$ anti-CD28 antibody (CD28.2) (purchased from BD Biosciences, Franklin Lakes, NJ).

Cells were stained using the following fluorochrome-labeled monoclonal antibodies: CD3-PerCP (BW264/56), CD4-APC (REA623), CD8-VioGreen (REA734), and CD40L-PE (5C8) (purchased from Miltenyi Biotec, Bergisch Gladbach, Germany). Viability dye Sytox blue from Invitrogen (Thermo Fisher Scientific, Waltham, MA) was used to exclude non-viable cells. Data was acquired on FACSAria II using Diva Software, both from BD Biosciences (Franklin Lakes, NJ), and analyzed on FlowJo software version 10.5.3 (Tree Star, Inc, Ashland, OR). Fluorescence-minus-one controls were performed in pilot studies. Gates for $\mathrm{CD} 40 \mathrm{~L}^{+} \mathrm{CD} 4 \mathrm{~T}$ cells were set using cells left unstimulated.

\section{In vitro $T$ cell expansion and cell sorting}

Thawed PBMCs were labeled with CFSE (Invitrogen, Carlsbad, CA) and cultured in AIM-V medium that contained L-glutamine, streptomycin sulfate at $50 \mu \mathrm{g} / \mathrm{ml}$, and gentamicin sulfate at $10 \mu \mathrm{g} / \mathrm{ml}$ (GIBCO, Grand Island, NY) and supplemented with 5\% human serum (One Lambda, Canoga Park, CA). Cells were stimulated for 7 days with $2 \mu \mathrm{g} / \mathrm{ml}$ of selected single peptides in addition to the master peptides pool. Cells were also stimulated with $4 \mu \mathrm{g} / \mathrm{ml}$ of a VZV lysate and used as a baseline control. Cells were 
stained using the following fluorochrome-labeled monoclonal antibodies: CD3-PerCP (BW264/56), CD4-APC (REA623), and CD8-VioGreen (REA734) (purchased from Miltenyi Biotec, Bergisch Gladbach, Germany). Viability dye Sytox blue from Invitrogen (Thermo Fisher Scientific, Waltham, MA) was used to exclude non-viable cells. Single viable CFSElow $\mathrm{CD}^{+} \mathrm{CD}^{-} \mathrm{CD}^{+} \mathrm{T}$ cells were sorted into 96-well PCR plates containing DNA/RNA Shield (Zymo Research, Irvine, CA) using FACSAria II and Diva Software (BD Biosciences, Franklin Lakes, NJ). For each of the selected single peptides, 500 cells were sorted in two technical replicates. For the master peptide pool and VZV lysate, 1000 cells were sorted in two technical replicates. Plates were immediately centrifuged and kept at $-20^{\circ} \mathrm{C}$ before TCR cDNA library preparation and sequencing.

\section{TCRß CDNA library preparation and sequencing of memory CD4 T cells}

DNA was extracted from sorted memory CD4 T cells using Quick-DNA Microprep kit (Zymo Research, Irvine, CA). ImmunoSEQ hsTCRB sequencing kit (Adaptive Biotechnologies, Seattle, WA) was used to profile TCR $\beta$ repertoire following the manufacturer's protocol.

After quality control using Fragment Analyzer (Agilent, Santa Clara, CA), libraries were pooled with equal volumes. The concentration of the final pool was measured with the Qubit dsDNA HS Assay kit (Thermo Fisher Scientific, Waltham, MA). The final pool was processed to be sequenced on the Miseq and NextSeq platforms (Illumina, San Diego, CA). Memory CD4 T cells of one of the vaccinees (H42, a non-converter) was not sequenced due to a capacity issue.

\section{TCR CDNA library preparation and sequencing of CFSE ${ }^{\text {low }}$ CD4 T cells}

RNA was extracted from each of the two technical replicates of sorted CFSElow CD4 T cells using Quick-RNA Microprep kit (Zymo Research, Irvine, CA). Without measuring the resulting RNA concentration, an RNA-based library preparation was used. The QIAseq Immune Repertoire RNA Library kit (Qiagen, Venlo, The Netherlands) amplifies $T C R \alpha,-\beta,-\gamma$, and $-\delta$ chains. After quality control using Fragment Analyzer (Agilent, Santa Clara, CA), concentration was measured with the Qubit dsDNA HS Assay kit (Thermo Fisher Scientific, Waltham, MA) and pools were equimolarly pooled and prepared for sequencing on the NextSeq platform (Illumina, San Diego, CA).

\section{TCRß sequence analysis}

TCR $\beta$ clonotypes were identified as previously described (De Neuter et al., 2019) where a unique TCR $\beta$ clonotype is defined as a unique combination of a $\mathrm{V}$ gene, CDR3 amino acid sequence, and J gene. All memory CD4 T cell DNA-based TCR $\beta$ sequencing reads were annotated using the immunoSEQ analyzer (v2) from Adaptive Biotechnologies. All small bulk RNA-based TCR sequencing reads were annotated using the MiXCR tool (v3.0.7) from the FASTQ files. As all RNA-based TCR sequencing experiments featured two technical replicates, only those TCR sequences that occurred in both replicates were retained and their counts were summed. Tracking of vaccine-specific TCR $\beta$ clonotypes is based on exact TCR $\beta$ CDR3 amino acid matches to remove any bias introduced by the different VDJ annotation pipelines. Non-HBsAg TCR annotations were done with the TCRex web tool (Gielis et al., 2019) on the July 24, 2019, using version 0.3.0. Breadth of the TCR sequences is defined as the number of unique TCR clonotypes belonging to a given set, divided by the total number of unique clonotypes in a repertoire. Inference of similar epitope binding between two TCR sequences is defined according to the Hamming distance (d) calculated on the CDR3 amino acid sequence with a cutoff $c=1$, as supported by prior research where it was shown that it was equivalent to the performance of more complex methods such as TCRdist (Dash et al., 2017) or k-mer clustering when applied to TCR $\beta$ chains only (De Neuter et al., 2018; Valkiers et al., 2021). All scripts used in this analysis are available via GitHub (https://github.com/pmeysman/HepBTCR, copy archived at swh:1:rev:bdda21dde671ac2e424e85bd270efafa719d4cb4, Meysman, 2022).

\section{Predictive HBs-response model}

From the single peptide data generated in the epitope mapping experiments, we aimed to create a predictive model to enumerate the HBs response from full TCR $\beta$ repertoire data. This approach allows for predictions that are epitope-specific rather than simply vaccine-specific. This model was applied in a leave-one-out cross-validation so that vaccine-specific TCR $\beta$ sequences from a vaccinee are not used to make predictions for the same vaccinee. While the predictive model is derived from 
epitope-specific data, it cannot be guaranteed that some of the expanded CD4 T cells detected in the in vitro assay are not due to bystander activation. Vaccine-specific TCR $\beta$ sequences of vaccinees who did not respond to the vaccine at day 60 (late-converters and non-converters) are expected to be more enriched in cells triggered to expand due to bystander activation. Indeed, running the set of vaccine-specific TCRß sequences through the TCRex webtool (Gielis et al., 2019) reveals that several TCRs are predicted to be highly similar to those reactive to the CMV NLVPMVATV epitope (enrichment $p$-value $<0.001$ when compared to the TCRex background repertoire) and the Mart-1 variant ELAGIGILTV epitope ( $p$-value < 0.001), which supports the notion that some of these TCR $\beta$ sequences might not be specific to HBsAg. This set of vaccine-specific TCR $\beta$ sequences can thus be used to make predictions about possible TCR $\beta$ sequences due to bystander activation of CD4 T cells, that is, common TCR $\beta$ sequences that might be present as false positives. The final output of the model is thus a ratio, $R_{\text {hbs, }}$ for any repertoire rep $_{i}$ describing a set of TCR $\beta$ sequences $t_{\text {repi: }}$ :

$$
\boldsymbol{R}_{\text {hbs }}\left(\boldsymbol{t}_{\text {repi }}\right)=\frac{\sum_{\text {pep }=1}^{54} \mid\left\{\boldsymbol{x} \in \boldsymbol{t}_{\text {repi }} \mid \text { min }_{y} \in t_{\text {tpep }} d(x, y)<c\right\}||\left|t_{\text {pep }}\right|}{\mid\left\{\boldsymbol{x} \in \boldsymbol{t}_{\text {repi }} \mid \text { min }_{y} \in t_{\text {bystander }} d(x, y)<c\right\}|/| t_{\text {bystander }} \mid}
$$

with $t_{p e p}$ as the set of TCR $\beta$ sequences occurring in both biological replicates for a single sample and a single peptide (pep) from the HBsAg epitope mapping experiment, and $t_{\text {bystander }}$ as the set of TCR $\beta$ sequences occurring in both biological replicates of the master peptide pool in any of the nonresponding samples. Thus, the ratio signifies the number of TCR clonotypes predicted to be reactive against one of the HBsAg peptides, normalized by a count of putative false positive predictions from bystander T cells.

\section{Ex vivo $T$ cell phenotyping of vaccine-specific $T$ cells}

Thawed PBMCs from each vaccinee were cultured in AIM-V medium that contained L-glutamine, streptomycin sulfate at $50 \mu \mathrm{g} / \mathrm{ml}$, and gentamicin sulfate at $10 \mu \mathrm{g} / \mathrm{ml}$ (GIBCO, Grand Island, NY) and supplemented with $5 \%$ human serum (One Lambda, Canoga Park, CA). Cells were stimulated for $6 \mathrm{hr}$ with $2 \mu \mathrm{g} / \mathrm{ml}$ of a master peptide pool representing the full length of the small surface envelope protein of $\mathrm{HB}$, in the presence of $1 \mu \mathrm{g} / \mathrm{ml}$ anti-CD40 antibody (HB14) (purchased from Miltenyi Biotec, Bergisch Gladbach, Germany) and $1 \mu \mathrm{g} / \mathrm{ml}$ anti-CD28 antibody (CD28.2) (purchased from BD Biosciences, Franklin Lakes, NJ). Cells were stained using the following fluorochrome-labeled monoclonal antibodies: CD3-BV510 (SK7), CD4-PerCP/Cy5.5 (RPA-T4), CD8-APC/Cy7 (SK1), CD45RA-AF488 (HI100), CD25-BV421 (M-A251), CD127-BV785 (A019D5), and CD137-PE (4-1BB) (purchased from BioLegend, San Diego, CA), CXCR5 (CD185)-PE-eFluor 610 (MU5UBEE) (from eBioscience, Thermo Fisher Scientific, Waltham, MA) and CD40L-APC (5C8) (purchased from Miltenyi Biotec, Bergisch Gladbach, Germany). Fixable viability dye Zombie NIR from BioLegend (San Diego, CA) was used to exclude non-viable cells. Data was acquired on FACSAria II using Diva Software, both from BD Biosciences (Franklin Lakes, NJ), and analyzed on FlowJo software version 10.5.3 (Tree Star, Inc, Ashland, OR) using gating strategy shown in Figure 4-figure supplement 1A. Fluorescence-minus-one controls were performed in pilot studies. Gates for $\mathrm{CD} 40 \mathrm{~L}^{+}$and $4-1 \mathrm{BB}^{+} \mathrm{CD} 4 \mathrm{~T}$ cells (Figure 4-figure supplement $1 \mathrm{~B}$ ) were set using cells left unstimulated (negative control contained DMSO at the same concentration used to solve peptide pools). In order to account for background expression of CD40L and 4-1BB on CD4 T cells, responses in cells left unstimulated were subtracted from the responses to peptides, and when peptides-specific $\mathrm{CD} 4 \mathrm{OL}^{+}$or $4-1 \mathrm{BB}^{+} \mathrm{CD} 4 \mathrm{~T}$ cells were not significantly higher than those detected for cells left unstimulated (using one-sided Fisher's exact test), values were mutated to zero.

\section{Statistics and data visualization}

The two-sided Fisher's exact test was used to evaluate the significance of relationship between early/ late-converters and CMV, EBV, or HSV seropositivity. For the visualization of marker expression, TCR $\beta$ counts and cell frequencies between time points or groups of vaccinees, ggplot2 (v3.3.2), ggpubr (v0.2.5), and rstatix (v0.7.0) packages in $\mathrm{R}$ were used. The Wilcoxon rank sum test and the Wilcoxon signed-rank test were used to compare two or more groups, with unpaired and paired analysis as necessary. Bonferroni correction was applied when multiple comparisons were made. The nonparametric Spearman's rank-order correlation was used to test for correlation. We used the following 
convention for symbols indicating statistical significance; ns $p>0.05,{ }^{\star} p \leq 0.05,{ }^{* *} p \leq 0.01$, ${ }^{* *} p \leq$ $0.001,{ }^{* * * *} \mathrm{p} \leq 0.0001$

\section{Acknowledgements}

We thank all the volunteers in the study, and all the nurses, lab technicians, researchers, and staff in the clinical biology laboratory of Antwerp University Hospital and the Centre for the Evaluation of Vaccination at the Vaccine and Infectious Disease Institute that were involved in the study. In addition, we wish to thank Nick de Vrij and Sebastiaan Valkiers for critically reading the manuscript for clarity. We further thank the reviewers and editors for their many suggestions that helped improve this work.

\section{Additional information}

Competing interests

Nina Keersmaekers: Viggo Van Tendeloo: The other authors declare that no competing interests exist.

Funding

\begin{tabular}{|c|c|c|}
\hline Funder & Grant reference number & Author \\
\hline Universiteit Antwerpen & & $\begin{array}{l}\text { George Elias } \\
\text { Esther Bartholomeus } \\
\text { Nicolas De Neuter }\end{array}$ \\
\hline $\begin{array}{l}\text { Research Foundation } \\
\text { Flanders }\end{array}$ & & $\begin{array}{l}\text { Pieter Meysman } \\
\text { Kris Laukens } \\
\text { Benson Ogunjimi }\end{array}$ \\
\hline $\begin{array}{l}\text { American Lebanese Syrian } \\
\text { Associated Charities }\end{array}$ & & $\begin{array}{l}\text { Aisha Souquette } \\
\text { Paul G Thomas }\end{array}$ \\
\hline $\begin{array}{l}\text { National Institute of Allergy } \\
\text { and Infectious Diseases }\end{array}$ & & $\begin{array}{l}\text { Aisha Souquette } \\
\text { Paul G Thomas }\end{array}$ \\
\hline
\end{tabular}

The funders had no role in study design, data collection and interpretation, or the decision to submit the work for publication.

Author contributions

George Elias, Formal analysis, Investigation, Methodology, Software, Visualization, Writing - original draft; Pieter Meysman, Conceptualization, Data curation, Formal analysis, Supervision, Visualization, Writing - review and editing; Esther Bartholomeus, Data curation, Formal analysis, Investigation, Methodology, Writing - original draft; Nicolas De Neuter, Formal analysis, Investigation; Nina Keersmaekers, Data curation, Formal analysis; Arvid Suls, Formal analysis, Investigation, Methodology, Writing - review and editing; Hilde Jansens, Hans De Reu, Marie-Paule Emonds, Investigation, Methodology; Aisha Souquette, Data curation, Formal analysis, Investigation, Writing - review and editing; Evelien Smits, Geert Mortier, Supervision, Writing - review and editing; Eva Lion, Methodology, Writing - review and editing; Paul G Thomas, Funding acquisition, Methodology, Supervision, Writing - review and editing; Pierre Van Damme, Philippe Beutels, Conceptualization, Project administration, Supervision, Writing - review and editing; Kris Laukens, Conceptualization, Data curation, Funding acquisition, Project administration; Viggo Van Tendeloo, Conceptualization, Funding acquisition, Project administration, Writing - review and editing; Benson Ogunjimi, Conceptualization, Funding acquisition, Project administration, Supervision, Writing - review and editing

\section{Author ORCIDs}

George Elias (iD) http://orcid.org/0000-0001-8419-9544

Pieter Meysman (iD http://orcid.org/0000-0001-5903-633X

Nicolas De Neuter (iD) http://orcid.org/0000-0002-6011-6457

Benson Ogunjimi (ib) http://orcid.org/0000-0002-0831-2063 
Ethics

Ethics.This study was approved by the Ethics Committee of the Antwerp University Hospital and University of Antwerp, Belgium (IRB 15/19/210). Written informed consent and consent to publish were obtained from all study participants. All experiments and methods were performed in accordance with the relevant guidelines and regulations when applicable.

Decision letter and Author response

Decision letter https://doi.org/10.7554/eLife.68388.sa1

Author response https://doi.org/10.7554/eLife.68388.sa2

\section{Additional files}

Supplementary files

- Supplementary file 1. List of 54 single peptides, each 15 amino acid (AA) long with an 11-AA overlap spanning the 226 AAs along the small S protein of hepatitis B (HB) surface antigen (HBsAg).

- Supplementary file 2. Overview of the single peptides tested for each vaccinee in the carboxyfluorescein succinimidyl ester (CFSE) assay.

- Transparent reporting form

Data availability

The sequencing data that support the findings of this study have been deposited on Zenodo (https://doi.org/10.5281/zenodo.3989144). Flow Cytometry Standard (FCS) data files with associated FlowJo workspaces are deposited at flowrepository.org under the following experiment names: epitope mapping: https://flowrepository.org/id/FR-FCM-Z2TN; in vitro T cell expansion: https://flowrepository.org/id/FR-FCM-Z2TM; ex vivo CD4 T cell assay: https://flowrepository.org/ id/FR-FCM-Z2TL.

The following dataset was generated:

\begin{tabular}{|c|c|c|c|c|}
\hline Author(s) & Year & Dataset title & Dataset URL & Database and Identifier \\
\hline Meysman P & 2020 & $\begin{array}{l}\text { Preexisting memory CD4 } \\
\text { T cells in naïve individuals } \\
\text { confer robust immunity } \\
\text { upon vaccination }\end{array}$ & $\begin{array}{l}\text { https://doi.org/10. } \\
\text { 5281/zenodo.3989144 }\end{array}$ & $\begin{array}{l}\text { Zenodo, } 10.5281 / \\
\text { zenodo.3989144 }\end{array}$ \\
\hline Elias G & 2020 & In vitro $T$ cell expansion & $\begin{array}{l}\text { https://flowrepository. } \\
\text { org/id/FR-FCM-Z2TM }\end{array}$ & $\begin{array}{l}\text { flowrepository, FR-FCM- } \\
\text { Z2TM }\end{array}$ \\
\hline Elias G & 2020 & ex vivo CD4 T cell assay & $\begin{array}{l}\text { https://flowrepository. } \\
\text { org/id/FR-FCM-Z2TL }\end{array}$ & $\begin{array}{l}\text { flowrepository, FR-FCM- } \\
\text { Z2TL }\end{array}$ \\
\hline Elias $G$ & 2020 & Epitope mapping & $\begin{array}{l}\text { https://flowrepository. } \\
\text { org/id/FR-FCM-Z2TN }\end{array}$ & $\begin{array}{l}\text { flowrepository, FR-FCM- } \\
\text { Z2TN }\end{array}$ \\
\hline
\end{tabular}

\section{References}

Bacher P, Schink C, Teutschbein J, Kniemeyer O, Assenmacher M, Brakhage AA, Scheffold A. 2013. Antigenreactive $T$ cell enrichment for direct, high-resolution analysis of the human naive and memory Th cell repertoire. Journal of Immunology 190:3967-3976. DOI: https://doi.org/10.4049/jimmunol.1202221, PMID: 23479226

Bacher P, Kniemeyer O, Teutschbein J, Thön M, Vödisch M, Wartenberg D, Scharf DH, Koester-Eiserfunke N, Schütte M, Dübel S, Assenmacher M, Brakhage AA, Scheffold A. 2014a. Identification of immunogenic antigens from Aspergillus fumigatus by direct multiparameter characterization of specific conventional and regulatory CD4+ T cells. Journal of Immunology 193:3332-3343. DOI: https://doi.org/10.4049/jimmunol. 1400776, PMID: 25172488

Bacher P, Kniemeyer O, Schönbrunn A, Sawitzki B, Assenmacher M, Rietschel E, Steinbach A, Cornely OA, Brakhage AA, Thiel A, Scheffold A. 2014b. Antigen-specific expansion of human regulatory T cells as a major tolerance mechanism against mucosal fungi. Mucosal Immunology 7:916-928. DOI: https://doi.org/10.1038/mi. 2013.107, PMID: 24301658

Becattini S, Latorre D, Mele F, Foglierini M, De Gregorio C, Cassotta A, Fernandez B, Kelderman S, Schumacher TN, Corti D, Lanzavecchia A, Sallusto F. 2015. T cell clones primed by pathogens or vaccines. Science 347:400-406. DOI: https://doi.org/10.1126/science.1260668, PMID: 25477212 
Bentebibel SE, Schmitt N, Banchereau J, Ueno H. 2011. Human tonsil B-cell lymphoma 6 (BCL6)-expressing CD4+ T-cell subset specialized for B-cell help outside germinal centers. PNAS 108:E488-E497. DOI: https:// doi.org/10.1073/pnas.1100898108, PMID: 21808017

Blom K, Braun M, Ivarsson MA, Gonzalez VD, Falconer K, Moll M, Ljunggren HG, Michaëlsson J, Sandberg JK. 2013. Temporal dynamics of the primary human T cell response to yellow fever virus 17D as it matures from an effector- to a memory-type response. Journal of Immunology 190:2150-2158. DOI: https://doi.org/10.4049/ jimmunol.1202234, PMID: 23338234

Booth NJ, McQuaid AJ, Sobande T, Kissane S, Agius E, Jackson SE, Salmon M, Falciani F, Yong K, Rustin MH, Akbar AN, Vukmanovic-Stejic M. 2010. Different proliferative potential and migratory characteristics of human CD4+ regulatory T cells that express either CD45RA or CD45RO. Journal of Immunology 184:4317-4326. DOI: https://doi.org/10.4049/jimmunol.0903781, PMID: 20231690

Brezar V, Godot V, Cheng L, Su L, Lévy Y, Seddiki N. 2016. T-Regulatory Cells and Vaccination "Pay Attention and Do Not Neglect Them": Lessons from HIV and Cancer Vaccine Trials. Vaccines 4:E30. DOI: https://doi.org/ 10.3390/vaccines4030030, PMID: 27608046

Campion SL, Brodie TM, Fischer W, Korber BT, Rossetti A, Goonetilleke N, McMichael AJ, Sallusto F. 2014. Proteome-wide analysis of HIV-specific naive and memory CD4(+) T cells in unexposed blood donors. The Journal of Experimental Medicine 211:1273-1280. DOI: https://doi.org/10.1084/jem.20130555, PMID: 24958850

Chou HH, Chien WH, Wu LL, Cheng CH, Chung CH, Horng JH, Ni YH, Tseng HT, Wu D, Lu X, Wang HY, Chen PJ, Chen DS. 2015. Age-related immune clearance of hepatitis $B$ virus infection requires the establishment of gut microbiota. PNAS 112:2175-2180. DOI: https://doi.org/10.1073/pnas.1424775112, PMID: 25646429

Curtsinger JM, Mescher MF. 2010. Inflammatory cytokines as a third signal for T cell activation. Current Opinion in Immunology 22:333-340. DOI: https://doi.org/10.1016/j.coi.2010.02.013, PMID: 20363604

Dash P, Fiore-Gartland AJ, Hertz T, Wang GC, Sharma S, Souquette A, Crawford JC, Clemens EB, Nguyen THO, Kedzierska K, La Gruta NL, Bradley P, Thomas PG. 2017. Quantifiable predictive features define epitopespecific T cell receptor repertoires. Nature 547:89-93. DOI: https://doi.org/10.1038/nature22383, PMID: 28636592

De Neuter N, Bittremieux W, Beirnaert C, Cuypers B, Mrzic A, Moris P, Suls A, Van Tendeloo V, Ogunjimi B, Laukens K, Meysman P. 2018. On the feasibility of mining CD8+ T cell receptor patterns underlying immunogenic peptide recognition. Immunogenetics 70:159-168. DOI: https://doi.org/10.1007/s00251-0171023-5, PMID: 28779185

De Neuter N, Bartholomeus E, Elias G, Keersmaekers N, Suls A, Jansens H, Smits E, Hens N, Beutels P, Van Damme P, Mortier G, Van Tendeloo V, Laukens K, Meysman P, Ogunjimi B. 2019. Memory CD4T cell receptor repertoire data mining as a tool for identifying cytomegalovirus serostatus. Genes and Immunity 20:255-260. DOI: https://doi.org/10.1038/s41435-018-0035-y, PMID: 29904098

DeWitt WS, Emerson RO, Lindau P, Vignali M, Snyder TM, Desmarais C, Sanders C, Utsugi H, Warren EH, McElrath J, Makar KW, Wald A, Robins HS. 2015. Dynamics of the cytotoxic T cell response to a model of acute viral infection. Journal of Virology 89:4517-4526. DOI: https://doi.org/10.1128/JVI.03474-14, PMID: 25653453

DeWitt WS, Smith A, Schoch G, Hansen JA, Matsen FA, Bradley P. 2018. Human T cell receptor occurrence patterns encode immune history, genetic background, and receptor specificity. eLife 7:e38358. DOI: https:// doi.org/10.7554/eLife.38358, PMID: 30152754

Elias G, Ogunjimi B, Van Tendeloo V. 2020. Activation-induced surface proteins in the identification of antigenresponsive CD4 T cells. Immunology Letters 219:1-7. DOI: https://doi.org/10.1016/j.imlet.2019.12.006, PMID: 31881234

Emerson RO, DeWitt WS, Vignali M, Gravley J, Hu JK, Osborne EJ, Desmarais C, Klinger M, Carlson CS, Hansen JA, Rieder M, Robins HS. 2017. Immunosequencing identifies signatures of cytomegalovirus exposure history and HLA-mediated effects on the T cell repertoire. Nature Genetics 49:659-665. DOI: https://doi.org/ 10.1038/ng.3822, PMID: 28369038

Esensten JH, Helou YA, Chopra G, Weiss A, Bluestone JA. 2016. CD28 Costimulation: From Mechanism to Therapy. Immunity 44:973-988. DOI: https://doi.org/10.1016/j.immuni.2016.04.020, PMID: 27192564

Farber DL, Yudanin NA, Restifo NP. 2014. Human memory T cells: generation, compartmentalization and homeostasis. Nature Reviews. Immunology 14:24-35. DOI: https://doi.org/10.1038/nri3567, PMID: 24336101

Fonseca VR, Agua-Doce A, Maceiras AR, Pierson W, Ribeiro F, Romão VC, Pires AR, da Silva SL, Fonseca JE, Sousa AE, Linterman MA, Graca L. 2017. Human blood Tfr cells are indicators of ongoing humoral activity not fully licensed with suppressive function. Science Immunology 2:eaan1487. DOI: https://doi.org/10.1126/ sciimmunol.aan1487, PMID: 28802258

Frentsch M, Arbach O, Kirchhoff D, Moewes B, Worm M, Rothe M, Scheffold A, Thiel A. 2005. Direct access to CD4+ T cells specific for defined antigens according to CD154 expression. Nature Medicine 11:1118-1124. DOI: https://doi.org/10.1038/nm1292, PMID: 16186818

Furman D, Jojic V, Sharma S, Shen-Orr SS, L. Angel CJ, Onengut-Gumuscu S, Kidd BA, Maecker HT, Concannon P, Dekker CL, Thomas PG, Davis MM. 2015. Cytomegalovirus infection enhances the immune response to influenza. Science Translational Medicine 7:281 ra43. DOI: https://doi.org/10.1126/scitrans/med. aaa2293, PMID: 25834109

Galson JD, Trück J, Clutterbuck EA, Fowler A, Cerundolo V, Pollard AJ, Lunter G, Kelly DF. 2016. B-cell repertoire dynamics after sequential hepatitis $B$ vaccination and evidence for cross-reactive B-cell activation. Genome Medicine 8:68. DOI: https://doi.org/10.1186/s13073-016-0322-z, PMID: 27312086 
Garner-Spitzer E, Wagner A, Paulke-Korinek M, Kollaritsch H, Heinz FX, Redlberger-Fritz M, Stiasny K, Fischer GF, Kundi M, Wiedermann U. 2013. Tick-Borne Encephalitis (TBE) and Hepatitis B Nonresponders Feature Different Immunologic Mechanisms in Response to TBE and Influenza Vaccination with Involvement of Regulatory T and B Cells and IL-10. The Journal of Immunology 191:2426-2436. DOI: https://doi.org/10.4049/ jimmunol.1300293, PMID: 23872054

Gielis S, Moris P, Bittremieux W, De Neuter N, Ogunjimi B, Laukens K, Meysman P. 2019. Detection of Enriched T Cell Epitope Specificity in Full T Cell Receptor Sequence Repertoires. Frontiers in Immunology 10:e2820. DOI: https://doi.org/10.3389/fimmu.2019.02820, PMID: 31849987

Ito T, Hanabuchi S, Wang YH, Park WR, Arima K, Bover L, Qin FXF, Gilliet M, Liu YJ. 2008. Two Functional Subsets of FOXP3+ Regulatory T Cells in Human Thymus and Periphery. Immunity 28:870-880. DOI: https:// doi.org/10.1016/j.immuni.2008.03.018, PMID: 18513999

Kachapati K, Adams DE, Wu Y, Steward CA, Rainbow DB, Wicker LS, Mittler RS, Ridgway WM. 2012. The B10 Idd9.3 locus mediates accumulation of functionally superior CD137(+) regulatory T cells in the nonobese diabetic type 1 diabetes model. Journal of Immunology 189:5001-5015. DOI: https://doi.org/10.4049/ jimmunol.1101013, PMID: 23066155

Keating GM, Noble S. 2003. Recombinant Hepatitis B Vaccine (Engerix-B??). Drugs 63:1021-1051. DOI: https:// doi.org/10.2165/00003495-200363100-00006, PMID: 12699402

Kim YH, Choi BK, Shin SM, Kim CH, Oh HS, Park SH, Lee DG, Lee MJ, Kim KH, Vinay DS, Kwon BS. 2011. 4-1BB triggering ameliorates experimental autoimmune encephalomyelitis by modulating the balance between Th17 and regulatory T cells. Journal of Immunology 187:1120-1128. DOI: https://doi.org/10.4049/jimmunol. 1002681, PMID: 21715692

Klarenbeek PL, Tak PP, van Schaik BDC, Zwinderman AH, Jakobs ME, Zhang Z, van Kampen AHC, van Lier RAW, Baas F, de Vries N. 2010. Human T-cell memory consists mainly of unexpanded clones. Immunology Letters 133:42-48. DOI: https://doi.org/10.1016/j.imlet.2010.06.011, PMID: 20621124

Kohler S, Bethke N, Böthe M, Sommerick S, Frentsch M, Romagnani C, Niedrig M, Thiel A. 2012. The early cellular signatures of protective immunity induced by live viral vaccination. European Journal of Immunology 42:2363-2373. DOI: https://doi.org/10.1002/eji.201142306, PMID: 22733156

Krangel MS. 2009. Mechanics of T cell receptor gene rearrangement. Current Opinion in Immunology 21:133139. DOI: https://doi.org/10.1016/j.coi.2009.03.009, PMID: 19362456

Lanteri MC, O'Brien KM, Purtha WE, Cameron MJ, Lund JM, Owen RE, Heitman JW, Custer B, Hirschkorn DF, Tobler LH, Kiely N, Prince HE, Ndhlovu LC, Nixon DF, Kamel HT, Kelvin DJ, Busch MP, Rudensky AY, Diamond MS, Norris PJ. 2009. Tregs control the development of symptomatic West Nile virus infection in humans and mice. The Journal of Clinical Investigation 119:3266-3277. DOI: https://doi.org/10.1172/ JCl39387, PMID: 19855131

Lin PH, Wong WI, Wang YL, Hsieh MP, Lu CW, Liang CY, Jui SH, Wu FY, Chen PJ, Yang HC. 2018. Vaccineinduced antigen-specific regulatory $T$ cells attenuate the antiviral immunity against acute influenza virus infection. Mucosal Immunology 11:1239-1253. DOI: https://doi.org/10.1038/s41385-018-0004-9, PMID: 29467445

Liu W, Putnam AL, Xu-Yu Z, Szot GL, Lee MR, Zhu S, Gottlieb PA, Kapranov P, Gingeras TR, Fazekas de St Groth B, Clayberger C, Soper DM, Ziegler SF, Bluestone JA. 2006. CD127 expression inversely correlates with FoxP3 and suppressive function of human CD4+ T reg cells. The Journal of Experimental Medicine 203:1701-1711. DOI: https://doi.org/10.1084/jem.20060772, PMID: 16818678

Lovelace P, Maecker HT. 2018. Multiparameter Intracellular Cytokine Staining. In Methods in Molecular Biology 1:151-166. DOI: https://doi.org/10.1007/978-1-4939-7346-0_9

Mason GM, Lowe K, Melchiotti R, Ellis R, Rinaldis E, Peakman M, Heck S, Lombardi G, Tree TIM. 2015. Phenotypic Complexity of the Human Regulatory T. Cell Compartment Revealed by Mass Cytometry. J. Immunol 195:2030-2037. DOI: https://doi.org/10.4049/jimmunol.1500703, PMID: 26223658

McHugh RS, Whitters MJ, Piccirillo CA, Young DA, Shevach EM, Collins M, Byrne MC. 2002. CD4(+)CD25(+) immunoregulatory $T$ cells: gene expression analysis reveals a functional role for the glucocorticoid-induced TNF receptor. Immunity 16:311-323. DOI: https://doi.org/10.1016/s1074-7613(02)00280-7, PMID: 11869690

Meireles LC, Marinho RT, Van Damme P. 2015. Three decades of hepatitis B control with vaccination. World Journal of Hepatology 7:2127-2132. DOI: https://doi.org/10.4254/wjh.v7.i18.2127, PMID: 26328023

Meysman P, De Neuter N, Gielis S, Bui Thi D, Ogunjimi B, Laukens K. 2019. On the viability of unsupervised T-cell receptor sequence clustering for epitope preference. Bioinformatics 35:1461-1468. DOI: https://doi.org/ 10.1093/bioinformatics/bty821, PMID: 30247624

Meysman P. 2022. Preexisting memory CD4 T cells in naïve individuals confer robust immunity upon vaccination. swh:1:rev:bdda21dde671ac2e424e85bd270efafa719d4cb4. Software Heritage. https://archive. softwareheritage.org/swh:1:dir:ba259d42b72b464259463236c4d69d7fdaba5d6f;origin=https://github.com/ pmeysman/HepBTCR;visit=swh:1:snp:9af24b74d71fc0603e410d162ef528d4e4a2a6ff;anchor=swh:1:rev:bdda 21dde671ac2e424e85bd270efafa719d4cb4

Mittler RS, Bailey TS, Klussman K, Trailsmith MD, Hoffmann MK. 1999. Anti-4-1BB monoclonal antibodies abrogate T cell-dependent humoral immune responses in vivo through the induction of helper T cell anergy. The Journal of Experimental Medicine 190:1535-1540. DOI: https://doi.org/10.1084/jem.190.10.1535, PMID: 10562327

Miyara M, Yoshioka Y, Kitoh A, Shima T, Wing K, Niwa A, Parizot C, Taflin C, Heike T, Valeyre D, Mathian A, Nakahata T, Yamaguchi T, Nomura T, Ono M, Amoura Z, Gorochov G, Sakaguchi S. 2009. Functional 
delineation and differentiation dynamics of human CD4T cells expressing the FoxP3 transcription factor. Immunity 30:899-911. DOI: https://doi.org/10.1016/j.immuni.2009.03.019, PMID: 19464196

Mohr A, Malhotra R, Mayer G, Gorochov G, Miyara M. 2018. Human FOXP3+ T regulatory cell heterogeneity. Clin. Transl. Immunol 7:e1005. DOI: https://doi.org/10.1002/cti2.1005

Pogorelyy MV, Minervina AA, Touzel MP, Sycheva AL, Komech EA, Kovalenko El, Karganova GG, Egorov ES, Komkov AY, Chudakov DM, Mamedov IZ, Mora T, Walczak AM, Lebedev YB. 2018. Precise tracking of vaccine-responding $T$ cell clones reveals convergent and personalized response in identical twins. PNAS 115:12704-12709. DOI: https://doi.org/10.1073/pnas.1809642115, PMID: 30459272

Precopio ML, Butterfield TR, Casazza JP, Little SJ, Richman DD, Koup RA, Roederer M. 2008. Optimizing peptide matrices for identifying T-cell antigens. Cytometry. Part A 73:1071-1078. DOI: https://doi.org/10. 1002/cyto.a.20646, PMID: 18781655

Reece WHH, Pinder M, Gothard PK, Milligan P, Bojang K, Doherty T, Plebanski M, Akinwunmi P, Everaere S, Watkins KR, Voss G, Tornieporth N, Alloueche A, Greenwood BM, Kester KE, McAdam KPWJ, Cohen J, Hill AVS. 2004. A CD4(+) T-cell immune response to a conserved epitope in the circumsporozoite protein correlates with protection from natural Plasmodium falciparum infection and disease. Nature Medicine 10:406-410. DOI: https://doi.org/10.1038/nm1009, PMID: 15034567

Reese TA, Bi K, Kambal A, Filali-Mouhim A, Beura LK, Bürger MC, Pulendran B, Sekaly R-P, Jameson SC, Masopust D, Haining WN, Virgin HW. 2016. Sequential Infection with Common Pathogens Promotes Humanlike Immune Gene Expression and Altered Vaccine Response. Cell Host \& Microbe 19:713-719. DOI: https:// doi.org/10.1016/j.chom.2016.04.003, PMID: 27107939

Ritchie AJ, Campion SL, Kopycinski J, Moodie Z, Wang ZM, Pandya K, Moore S, Liu MKP, Brackenridge S, Kuldanek K, Legg K, Cohen MS, Delwart EL, Haynes BF, Fidler S, McMichael AJ, Goonetilleke N. 2011. Differences in HIV-specific T cell responses between HIV-exposed and -unexposed HIV-seronegative individuals. Journal of Virology 85:3507-3516. DOI: https://doi.org/10.1128/JVI.02444-10, PMID: 21270166

Robinson CM, Pfeiffer JK. 2014. Viruses and the Microbiota. Annual Review of Virology 1:55-69. DOI: https:// doi.org/10.1146/annurev-virology-031413-085550, PMID: 25821837

Rudensky AY. 2011. Regulatory T cells and Foxp3. Immunological Reviews 241:260-268. DOI: https://doi.org/ 10.1111/j.1600-065X.2011.01018.x, PMID: 21488902

Rudolph MG, Stanfield RL, Wilson IA. 2006. How TCRs bind MHCs, peptides, and coreceptors. Annual Review of Immunology 24:419-466. DOI: https://doi.org/10.1146/annurev.immunol.23.021704.115658, PMID: 16551255

Sallusto F, Lanzavecchia A, Araki K, Ahmed R. 2010. From vaccines to memory and back. Immunity 33:451-463. DOI: https://doi.org/10.1016/j.immuni.2010.10.008, PMID: 21029957

Sanchez AM, Zhu J, Huang X, Yang Y. 2012. The development and function of memory regulatory T cells after acute viral infections. Journal of Immunology 189:2805-2814. DOI: https://doi.org/10.4049/jimmunol.1200645, PMID: 22855712

Schoenbrunn A, Frentsch M, Kohler S, Keye J, Dooms H, Moewes B, Dong J, Loddenkemper C, Sieper J, Wu P, Romagnani C, Matzmohr N, Thiel A. 2012. A converse 4-1BB and CD40 ligand expression pattern delineates activated regulatory $T$ cells (Treg) and conventional T cells enabling direct isolation of alloantigen-reactive natural Foxp3+ Treg. Journal of Immunology 189:5985-5994. DOI: https://doi.org/10.4049/jimmunol.1201090, PMID: 23162126

Seddiki N, Santner-Nanan B, Martinson J, Zaunders J, Sasson S, Landay A, Solomon M, Selby W, Alexander SI, Nanan R, Kelleher A, Fazekas de St Groth B. 2006. Expression of interleukin (IL)-2 and IL-7 receptors discriminates between human regulatory and activated T cells. The Journal of Experimental Medicine 203:1693-1700. DOI: https://doi.org/10.1084/jem.20060468, PMID: 16818676

Sewell AK. 2012. Why must T cells be cross-reactive? Nature Reviews. Immunology 12:669-677. DOI: https:// doi.org/10.1038/nri3279, PMID: 22918468

Shouval D. 2003. Hepatitis B vaccines. Journal of Hepatology 39:S70-S76. DOI: https://doi.org/10.1016/ s0168-8278(03)00152-1, PMID: 14708681

Su LF, Davis MM. 2013. Antiviral memory phenotype T cells in unexposed adults. Immunological Reviews 255:95-109. DOI: https://doi.org/10.1111/imr.12095, PMID: 23947350

Su LF, Kidd BA, Han A, Kotzin JJ, Davis MM. 2013. Virus-Specific CD4+ Memory-Phenotype T Cells Are Abundant in Unexposed Adults. Immunity 38:373-383. DOI: https://doi.org/10.1016/j.immuni.2012.10.021, PMID: 23395677

Turner SJ, La Gruta NL, Kedzierska K, Thomas PG, Doherty PC. 2009. Functional implications of T cell receptor diversity. Current Opinion in Immunology 21:286-290. DOI: https://doi.org/10.1016/j.coi.2009.05.004, PMID: 19524428

Valkiers S, Van Houcke M, Laukens K, Meysman P, Boeva DV. 2021. ClusTCR: a python interface for rapid clustering of large sets of CDR3 sequences with unknown antigen specificity. Bioinformatics 37:4865-4867. DOI: https://doi.org/10.1093/bioinformatics/btab446, PMID: 34132766

Wickham H. 2016. Modelling for Visualisation. Ggplot2. Cham: Springer. DOI: https://doi.org/10.1007/978-3319-24277-4

Wilson DB, Wilson DH, Schroder K, Pinilla C, Blondelle S, Houghten RA, Garcia KC. 2004. Specificity and degeneracy of T cells. Molecular Immunology 40:1047-1055. DOI: https://doi.org/10.1016/j.molimm.2003.11. 022

Wing JB, Ise W, Kurosaki T, Sakaguchi S. 2014. Regulatory T Cells Control Antigen-Specific Expansion of Tfh Cell Number and Humoral Immune Responses via the Coreceptor CTLA-4. Immunity 41:1013-1025. DOI: https:// doi.org/10.1016/j.immuni.2014.12.006, PMID: 25526312 
Winkler ES, Thackray LB. 2019. A long-distance relationship: the commensal gut microbiota and systemic viruses. Current Opinion in Virology 37:44-51. DOI: https://doi.org/10.1016/j.coviro.2019.05.009

Wu T, Li F, Chen Y, Wei H, Tian Z, Sun C, Sun R. 2019. CD4+ T Cells Play a Critical Role in Microbiota-Maintained Anti-HBV Immunity in a Mouse Model. Frontiers in Immunology 10:e927. DOI: https://doi.org/10.3389/fimmu. 2019.00927, PMID: 31114580

Yuen MF, Chen DS, Dusheiko GM, Janssen HLA, Lau DTY, Locarnini SA, Peters MG, Lai CL. 2018. Hepatitis B virus infection. Nature Reviews Disease Primers 4:18035. DOI: https://doi.org/10.1038/nrdp.2018.35, PMID: 29877316

Zheng G, Wang B, Chen A. 2004. The 4-1BB costimulation augments the proliferation of CD4+CD25+ regulatory T cells. Journal of Immunology 173:2428-2434. DOI: https://doi.org/10.4049/jimmunol.173.4.2428 